\title{
Risk-based methodology for parameter calibration of a reservoir flood control model
}

\author{
P. Bianucci ${ }^{1}$, A. Sordo-Ward ${ }^{2}$, J. I. Pérez ${ }^{1}$, J. García-Palacios ${ }^{1}$, L. Mediero ${ }^{1}$, and L. Garrote ${ }^{1}$ \\ ${ }^{1}$ Department of Civil Engineering, Hydraulics and Energy, Technical University of Madrid, Madrid, Spain \\ ${ }^{2}$ Department of Civil Engineering, Hydr@m Research Group, Technical University of Cartagena, Cartagena, Spain \\ Correspondence to: P. Bianucci (paola.bianucci@upm.es)
}

Received: 30 September 2012 - Published in Nat. Hazards Earth Syst. Sci. Discuss.: Revised: 19 December 2012 - Accepted: 10 January 2013 - Published: 18 April 2013

\begin{abstract}
Flash floods are of major relevance in natural disaster management in the Mediterranean region. In many cases, the damaging effects of flash floods can be mitigated by adequate management of flood control reservoirs. This requires the development of suitable models for optimal operation of reservoirs. A probabilistic methodology for calibrating the parameters of a reservoir flood control model (RFCM) that takes into account the stochastic variability of flood events is presented. This study addresses the crucial problem of operating reservoirs during flood events, considering downstream river damages and dam failure risk as conflicting operation criteria. These two criteria are aggregated into a single objective of total expected damages from both the maximum released flows and stored volumes (overall risk index). For each selected parameter set the RFCM is run under a wide range of hydrologic loads (determined through Monte Carlo simulation). The optimal parameter set is obtained through the overall risk index (balanced solution) and then compared with other solutions of the Pareto front. The proposed methodology is implemented at three different reservoirs in the southeast of Spain. The results obtained show that the balanced solution offers a good compromise between the two main objectives of reservoir flood control management.
\end{abstract}

\section{Introduction}

Most of the dams are multipurpose, usually involving flood control and other purposes such as hydropower, ecological discharges, drought mitigation, among others, which may be in conflict. The correct functioning of such systems is based on tradeoffs between the different purposes. However, in semiarid regions, floods are exceptional and temporary events that may involve operating policies practically independent from other controls.

Floods are one of the most relevant categories of natural hazards (Correia et al., 1999; ICOLD, 2006). More than $80 \%$ of the losses from weather-driven disasters in Spain were caused by floods (Barredo et al., 2012). Dam-reservoir systems offer efficient means of flood control (ICOLD, 2003, 2006). However, dams introduce important risk factors, such as failure due to dam overtopping or induced floods due to flawed spillway operation (Valdés and Marco, 1995). The adequate definition of flood operating rules is an essential component of flood risk management downstream of reservoirs. Population levels and the assets protected by such large-scale infrastructure have risen, accentuating the negative consequences of dam failure (ICOLD, 2006). Therefore, more efficient operation of existing reservoirs has become necessary (Labadie, 2004). That may be achieved with the help of optimisation models for reservoir operation.

Operation of a reservoir during floods involves a compromise between the released flows and the stored volumes, to neither damage the river downstream nor endanger the safety of the structure (Wurbs, 2005). Its nature is essentially multiobjective.

Some authors (Needham et al., 2000; Raman and Chandramouli, 1996; Chang, 2008; Ngo et al., 2007) propose models that optimise the reservoir operation using a limited number of events (recorded floods, events associated to selected return periods, etc.). Thus, the performance of the reservoir operation model is limited to the specific hydrologic conditions of those events. Furthermore, the 
performance of most reservoir operation models depends on parameters (coefficients of the objective function, penalty functions, etc.) that must be provided by users that are not experienced in mathematical programming. Such limitations contribute to increasing the gap between the theoretical development and practical application of optimisation models to reservoir operation (Labadie, 2004).

To guarantee that the operating policies obtained with a given model are optimal, these should display fitting behaviour for a wide and representative array of flood events. The synthetic generation of inflow hydrographs and stochastic prediction of flood events (stochastic approach) allows the ensemble of inputs to be representative of heavy to extreme flood events and also permits consideration of the uncertainty associated with the input variables (Alemu et al., 2011; Faber and Stedinger, 2001). The stochastic approach is also of interest because it allows risk analysis, which is relevant for the reservoir flood control operation in connection with floodplain management (Jain et al., 1992; Lund, 2002; Apel et al., 2004). Furthermore, Valdés and Marco (1995) highlighted the importance of including the risk of dam overtopping in reservoir operation models.

The methods used to address optimisation of multiobjective problems can be grouped into the two following approaches: through an aggregation method (aggregated parameter approach, APA) and a dominance criterion (Pareto dominance approach, PDA) or Pareto-optimal solutions. In the former, the multiobjective problem becomes a single objective, whereas in the latter its multiobjective nature is maintained throughout the analysis (Khu and Madsen, 2005).

Some authors proposed multiobjective approaches based on determining the Pareto solutions to optimise the operation of reservoirs or the management of flood mitigation measures (Rani and Moreira, 2010). Those studies offer a set of "good" solutions to assist decision makers (DMs) in reaching a rational choice. Cioffi and Gallerano (2012) optimised a reservoir considering hydropower and ecological aspects, using a multiobjective methodology. They adopted the maximum curvature criterion to select one solution from among the nondominated solutions, because the Pareto front they obtained was convex and continuous. Malekmohammadi et al. (2011) proposed an optimisation model for a multipurpose reservoir system, explicitly including the expected flood damage in the objective function formulation. They also implemented a method for outranking the Pareto solutions, which requires definition of many parameters and incorporating the preferences of DMs to select a particular solution. They estimated these parameters for some floods with selected return periods.

RFCMs may be parameterised to facilitate their application to different case studies or to simplify their resolution (Koutsoyiannis et al., 2002). Thus, a question arises: How to calibrate these parameters to ensure an optimal performance of the RFCM? In a stochastic framework, automatic parameter calibration is a promising alternative, although it first requires the definition of a criterion for comparison among different reservoir operations during a flood event.

Automatic calibration and explicit treatment of the uncertainty associated with the parameters have been extensively applied to rainfall-runoff and flow prediction models (Duan et al., 1992; Yapo et al., 1996, 1998; Gupta et al., 1998, 1999; Madsen, 2003; Mediero et al., 2011). In the sphere of reservoir operation models, the application of automatic calibration techniques is somewhat sparse. On occasions, calibration of the parameters of the RFCM is performed with the aim of obtaining operating policies similar to the recorded ones (Ginn and Houk, 1989; USACE, 1999), which may be far away from optimal operation rules. Some authors tune the parameters of a RFCM to obtain the optimal performance in a few selected events (Wei and Hsu, 2008; Malekmohammadi et al., 2011; Ngo et al., 2007). Koutsoyiannis et al. (2002) applied a parameterisation-simulation-optimisation approach to two reservoir systems with the purpose of supplying water for different uses. They adjusted the parameters through optimisation during a simulation interval and evaluated the objective function of the overall simulation period. Ngo et al. (2007) optimised the flood control strategies of a hydropower reservoir in two steps applying PDA. They found that the balanced solution (objectives equally weighted) provides a good compromise between the objectives. However, they calibrated using four design floods in the first step, and five samples for the second step. Other works transfer the setting of the parameters to the reservoir managers (such as Kim et al., 2007), though they are generally unfamiliar with the formulation of optimisation models hindering their correct definition (Labadie, 2004).

This paper presents a methodology for probabilistic calibration of the parameters of a RFCM. This approach is similar to that suggested by Ngo et al. (2007), however a stochastic approach is considered here. In order to do this, the RFCM is run with different sets of parameters suitably selected, under a representative flash floods ensemble with a wide range of return periods $(T r)$ and short duration ( $<1$ week). The expected damages from both the maximum flow released and maximum storage are aggregated within a single indicator, hereinafter referred to as overall risk index. The overall risk index is then used to select the most suitable parameter set. The solution obtained by using the overall risk index is then assessed in the framework of the Pareto solutions. The methodology is general, and can be applied to any type of RFCM, including a proposed set of operating rules that can be parameterised.

\section{Methodology}

The problem associated with the operation of a reservoir in the case of a flood event is fundamentally of a multiobjective nature, given that the purpose is on the one hand to avoid spilling discharges that cause damage downstream, and on 
the other hand to prevent reservoir water levels from reaching a point that might jeopardise dam safety. The conflicting nature of these two objectives is not always apparent. For small floods, dam safety is of little concern for dam managers, since dams are designed to withstand floods of a certain magnitude safely. If design floods are never exceeded dam safety will be of little concern, however the possibility of larger floods causes that the dam safety become a priority. Simulating floods of this magnitude enables dam managers to determine to what extent the dam can stand them. When faced with these situations, dam managers must prioritise the safety of the dam over the downstream impact of dam spillage, since a dam failure would cause a much greater damage. These two objectives, floodplain protection and dam safety, must be adequately balanced while calibrating a RFCM.

Most RFCMs maximise or minimise an objective function, but they also contain certain parameters which require definition. The efficacy of the RFCM depends, to a significant extent, both on appropriate formulation of the objective function and on adequate parameter values. Therefore, calibration serves as an essential facet of the model.

In this work, calibration of the RFCM parameters refers to the determination of the parameter values of the RFCM that enables it to operate satisfactorily for a wide range of flood events.

\subsection{The conceptual framework}

A RFCM $\pi$ usually has one or more variables associated that constitute the input $U$ of the RFCM, such as the inflow hydrograph $Q^{\mathrm{I}}(t)$ and the initial volume $V\left(t_{0}\right)$. The output $Y$ of the RFCM can be represented by the outflow hydrograph $Q^{\mathrm{O}}(t)$ and the time evolution of stored volume in the reservoir $V(t)$. If the model depends on the set $\theta$ of $R$ parameters, model behaviour is represented by (Eq. 1)

$\pi[\boldsymbol{\theta}, U]=Y$.

Thus, for an equal input $Q^{\mathrm{I}}(t)$ and $V\left(t_{0}\right)$, Eq. (1) will provide different outputs $Q^{\mathrm{O}}(t)$ and $V(t)$ according to the values of $\theta$. If a single inflow hydrograph is considered, for a fixed parameter set, a single outflow hydrograph (and the corresponding evolution of storage) will be obtained (deterministic approach, Fig. 1a).

However, in the context of flood risk analysis, the input variables $Q^{\mathrm{I}}(t)$ and $V\left(t_{0}\right)$ are random and may be characterised through the cumulative distribution functions of any characteristic (such as peak flow, volume, etc.) of the ensemble of flood hydrographs $F\left[Q^{\mathrm{I}}(t)\right]$, and of initial states $F\left[V\left(t_{0}\right)\right]$. Using the model, the cumulative distribution functions of the output variables are obtained: $F\left[Q^{\mathrm{O}}(t)\right]$ and $F[V(t)]$. This may be named as a stochastic approach (Fig. 1b).

If calibration of the parameter set is undertaken considering the deterministic approach, the selected parameter set may not be optimal for hydrologic situations that differ from those used in the adjustment process. Under the stochastic approach, definition of the set of parameters $\theta$ that lead to the behaviour of $\pi$ being generally optimal for the input ensemble is of interest, and may be undertaken through risk analysis and expected damages calculation. The methodological approach is sketched in Fig. 1c.

Definition of the set of parameters that optimise the behaviour of the model, under a given set of inputs, involves establishing an objective criterion that specifies what is to be understood by optimum, as well as devising procedures that enable identification of the parameters that optimise the capacity of the model. In order to address this task, the proposed methodology is structured in three steps: first, characterisation; second, synthesisation; and third, comparison of the performance of the model for each parameter set $\theta$.

Let $\boldsymbol{\theta}_{g}$ be a set of parameters belonging to feasible parameter space to be compared during the calibration process, where $g=1, \ldots, G$, being $G$ the total number of combinations analysed. For each stochastic realisation $g$ an ensemble output will be obtained (Eq. 2):

$\pi\left[\boldsymbol{\theta}_{g}, F\left[Q^{\mathrm{I}}(t)\right], F\left[V\left(t_{0}\right)\right]\right]=\left[F\left[Q^{\mathrm{O}}(t)\right], F[V(t)]\right]_{g}$.

The output of the realisation is an ensemble of outflow hydrographs and time series of stored volumes.

\subsubsection{Characterisation}

This structure is too complex to handle in the calibration procedure. For this reason, in the first step, the model performance is evaluated by means of random variables of characterisation named as $\omega_{k}$, which are in turn functions of the output variables (Eq. 3) through the operator $\varphi_{k}$., with $k=1, \ldots, K$, being $K$ the number of characterisation variables.

$\omega_{k}=\phi_{k}\left[Q^{\mathrm{O}}(t), V(t)\right]$

These variables may represent, among others, the maximum released flows, maximum reservoir volume, total released volume, maximum flow gradient, or the time during which a given volume in the reservoir is exceeded. In the case of the first two examples, the operator will be $\varphi_{k}=\max ($.).

Should the output variables be represented by the respective cumulative distribution functions, the cumulative distribution of the random variables of characterisation $F\left[\omega_{k}\right]$, can be determined from Eq. (4).

$F\left[\omega_{k}\right]=F\left\{\phi_{k}\left[Q^{\mathrm{O}}(t)\right], \phi_{k}[V(t)]\right\}$

The functions $F\left[\omega_{k}\right]$ characterise different aspects that are of relevance in the problem. From these functions, the objective functions that enable evaluation of the model performance for each set of parameters $\boldsymbol{\theta}_{g}$ are defined. 
DETERMINISTIC APPROACH

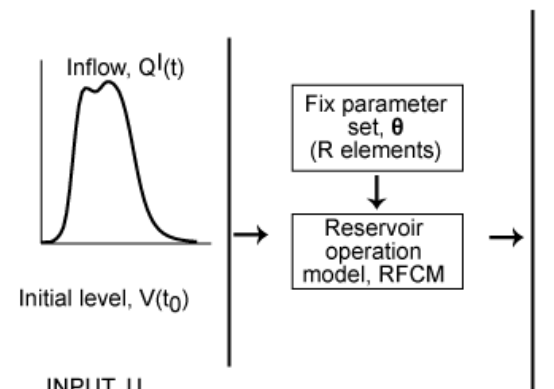

INPUT, U

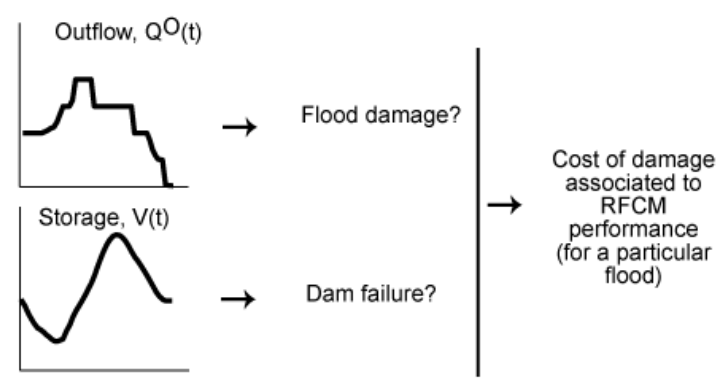

OUTPUT, Y a)

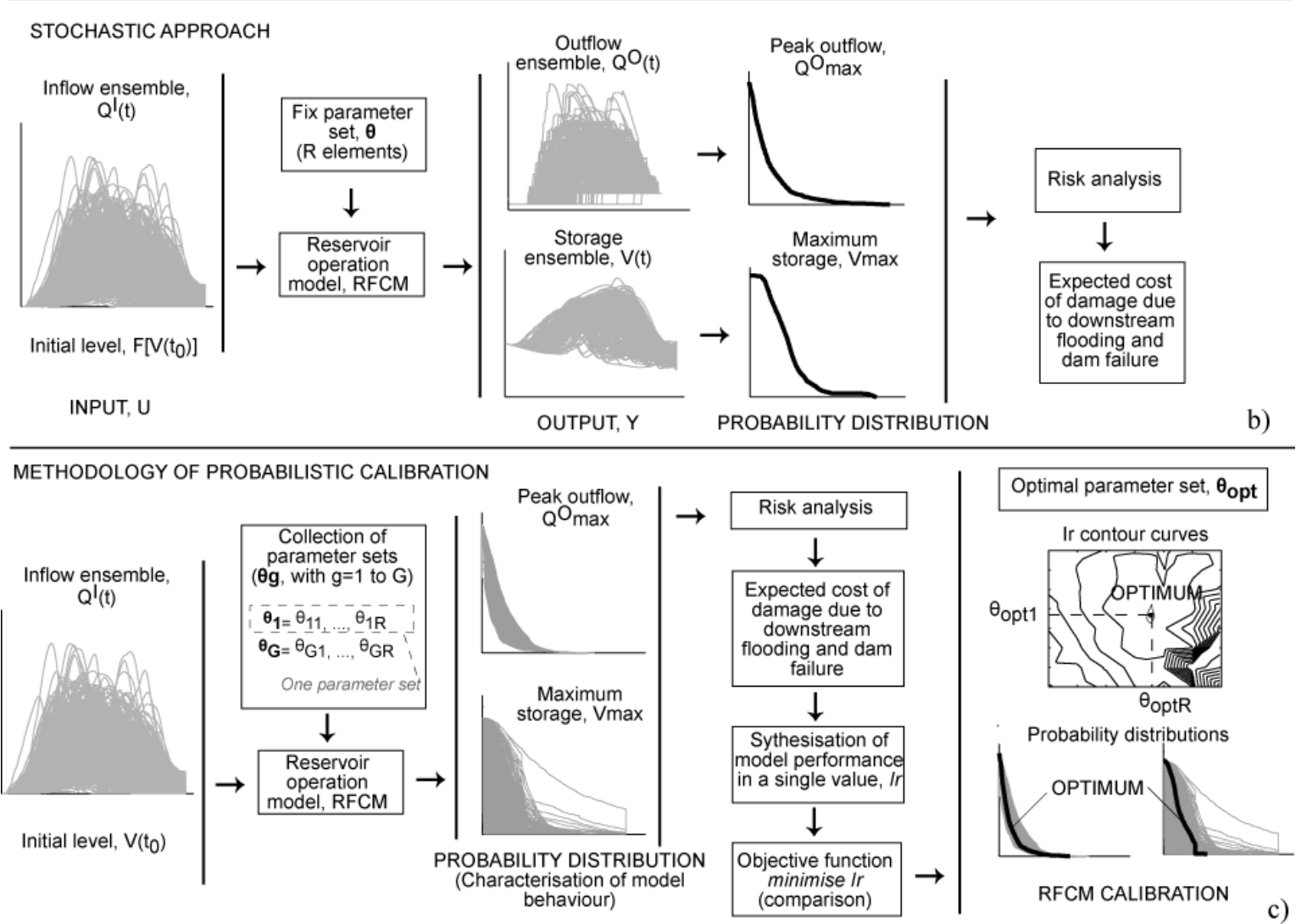

Fig. 1. Conceptual framework and methodological approach.

\subsubsection{Synthesisation}

Should the objective functions be comparable, the multiobjective problem can be solved by means of an aggregation method. Following such an APA approach, synthesisation of the behavioural patterns of $\pi$ characterised by $F\left[\omega_{k}\right]$ is performed through definition of the function $\Psi$ (summary function) that operates over the distribution functions of the random variables of characterisation (Eq. 5), with the result being a unique numerical value $I_{g}$ for each parameter set.

$\boldsymbol{\theta}_{g} \rightarrow I_{g}=\Psi\left\{F\left[\omega_{1}\right], \ldots, F\left[\omega_{k}\right]\right\}_{g}$
In this sense, the numerical value $I_{g}$ can be understood as a performance function of the parameter set $\boldsymbol{\theta}_{g}$ (Eq. 6).

$I_{g}=\psi\left\{\boldsymbol{\theta}_{g}\right\}$

\subsubsection{Comparison}

Once the performance of the model has been synthesised with the value $I_{g}$, any two parameter sets $\theta_{1}$ and $\theta_{2}$ that have the values $I_{1}$ and $I_{2}$ respectively associated, can be compared by comparing the values $I_{1}$ and $I_{2}$. Thus, in the case of minimisation, if $I_{2}<I_{1}$, the parameter set $\theta_{2}$ is considered as being more suitable than $\theta_{1}$. Therefore, the optimum parameter set can be identified according to the established criterion (Eq. 7). 
$I_{\text {opt }}=\min _{g \in G}\left[I_{g}\left(\boldsymbol{\theta}_{g}\right)\right] \Rightarrow \boldsymbol{\theta}_{\text {opt }}$,

where the solution is the set $\theta_{\text {opt }}$.

In the case that the objective functions are noncommensurable, or that explicit dealing with the multiobjective characteristic is sought, the Pareto dominance approach should be adopted. In order to determine the set of Pareto solutions, it is also necessary to establish the objective functions that assess different aspects of the problem. From the contrasts among such objective functions, compromise solutions are obtained. These allow ring-fencing of feasible solutions, in turn facilitating analysis by the dam operators and the subsequent choice of the most fitting solution.

The proposed methodological framework can be applied to any parametric RFCM.

\subsection{Model implementation}

To guide the reader in the implementation of the suggested approach, a scheme of the process is shown in Fig. 2.

As mentioned above the RFCM is run for an ensemble of flood hydrographs, assumed as being representative of the hydrologic forcing of the dam. In order to generate such ensemble, a Monte Carlo simulation framework, proposed by Sordo-Ward et al. (2012), was applied. This framework comprises a series of aggregate and integrated models and constitutes an event-based hydrometeorological model.

A random sample of 1000 values of probability of occurrence $(p)$ was produced to stochastically generate the rainfall events. For each sub-basin, the maximum daily precipitation (for each return period, $T r$, considered, being $\operatorname{Tr}=1 / p$ ) was estimated according to an extreme value distribution, SQRT-ETmax (square root exponential type distribution of the maximum) (Etoh et al., 1986; Ministerio de Fomento, 1999). Then, the total volume for a duration $D$ selected was calculated based on the intensity-duration-frequency curves (IDF) proposed by the Spanish Ministry of Public Works (MOPU, 1990) and recommended by the Spanish National Committee on Large Dams (SPANCOLD, 1997). The temporal distribution of each storm was determined using an autoregressive moving average (ARMA) model.

Inflow hydrographs were obtained through the application of the hydrologic model that simulates the main physical processes involved. For the rainfall-runoff transformation the curve number method was applied (SCS, 1972). The generation of hydrographs was conducted using the Soil Conservation Service dimensionless unit hydrograph procedure (SCS, 1972). The flood routing was performed by applying the Muskingum method (McCarthy, 1938).

For a more detailed description of the flood ensemble generation model the reader may refer to Sordo-Ward et al. (2012).

Hydrographs are characterised by several variables such as peak flow, volume, and total duration, among others. The

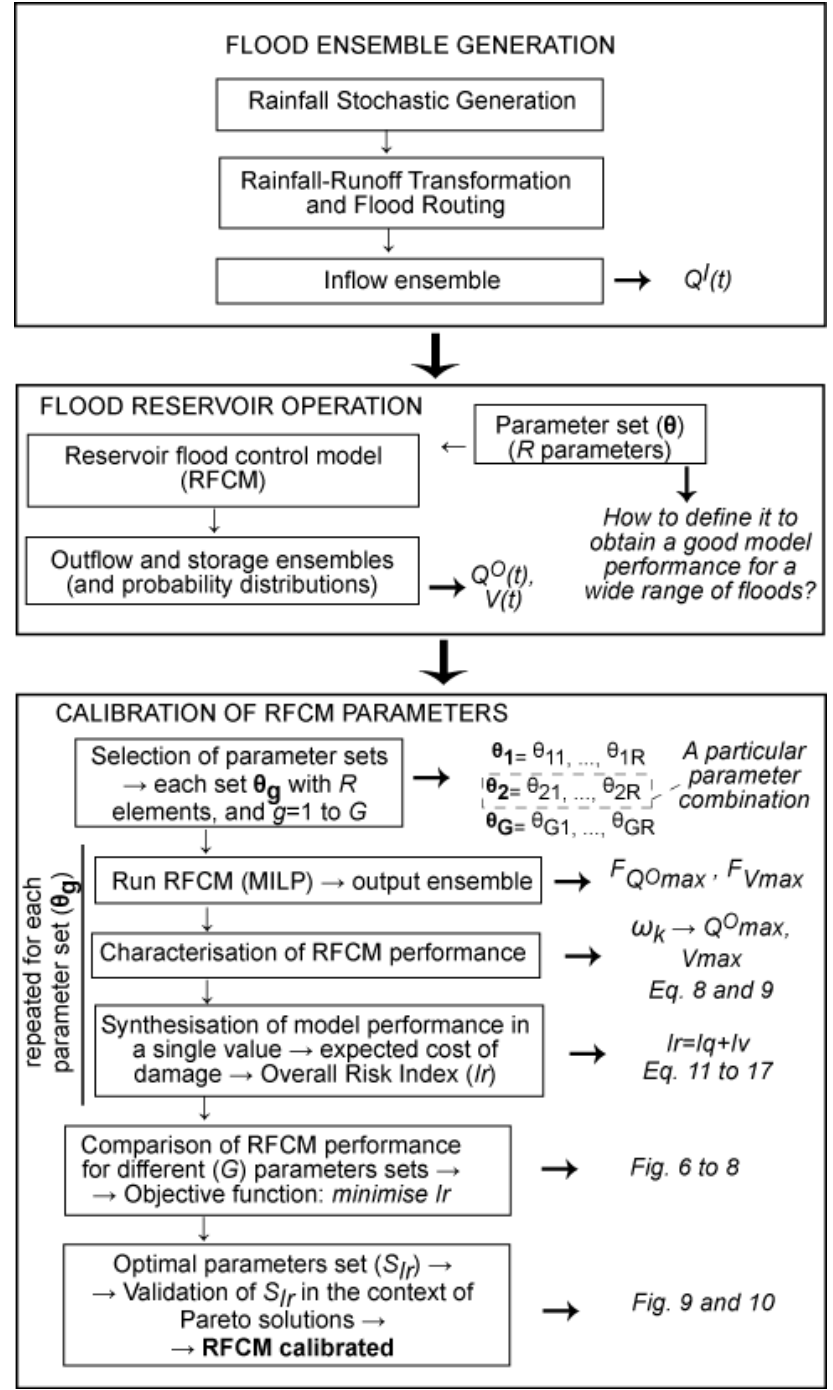

Fig. 2. Implementation of the methodology.

magnitude of a flood, in order to determine the maximum event of the year, may be characterised by each of the variables mentioned, or by derived variables such as the maximum reservoir level, peak released flow, and damage caused to the downstream channel. As these derived aspects are related to the flood control operation, which we are trying to determine, in this work we considered the peak flow frequency law extract from the ensemble of flood hydrographs.

For the implementation of the methodology, the input $U$ of the model $\pi$ was represented through the initial state vector $\boldsymbol{V}_{n, 0}$ and the inflow matrix $\mathbf{Q}_{n, t}^{\mathrm{I}}$, with $n=1, \ldots, N$, and $t=1, \ldots, T$, being $N$ the number of events (hydrographs) considered and $T$ the maximum flood event duration. The output $Y$ was represented by means of the outflow matrix (released flows), considering both the outlets and spillways $\left(\mathbf{Q}_{n, t}^{\mathrm{O}}\right)$, and the storage matrix $\left(\mathbf{V}_{n, t}\right)$. 


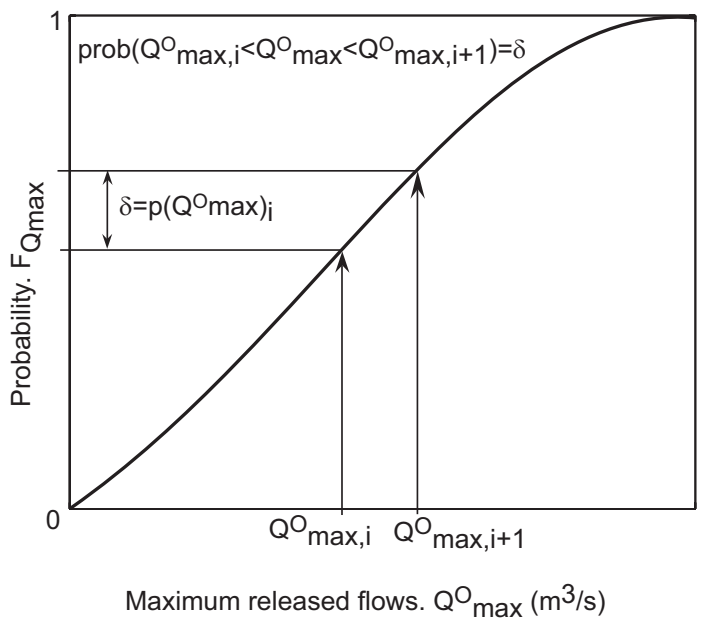

Fig. 3. Probabilities involved in the determination of $I q$ and $I v$.

The random variables of characterisation were defined from the operator $\varphi_{k}=\max ($.$) . The resulting characterisa-$ tion variables $\left(\omega_{k}\right)$ were the maximum released flow (Eq. 8) $\left(Q_{\max , n}^{\mathrm{O}}\right)$ and the maximum volume reached (Eq. 9) during the abatement of each flood event $\left(V_{\max , n}\right)$. These are of particular relevance in the assessment of flood control reservoir operation:

$\omega_{1}^{n}=Q_{\max , n}^{\mathrm{O}}=\max _{t}\left(Q_{n, t}^{\mathrm{O}}\right)$

$\omega_{2}^{n}=V_{\max , n}=\max _{t}\left(V_{n, t}\right)$,

where $\omega_{k}^{n}$ is the value that takes the variable $\omega_{k}$ for each hydrograph $n$. Therefore, $\mathbf{Q}_{\max }^{\mathrm{O}}$ and $\boldsymbol{V}_{\max }$ are the vectors of maximum flows and maximum storage of the output ensemble, respectively.

The objective functions proposed for evaluation of the two main aspects related to flood operations, are the released flow risk index $(I q)$ and the storage risk index $(I v)$. These partial risk indices operate over the probability distributions of the variables of characterisation $F\left[\omega_{1}\right]$ and $F\left[\omega_{2}\right]$, respectively. The empirical cumulative distributions of $\omega_{1}$ and $\omega_{2}$ were estimated by ranking the events and assigning frequencies according to the Gringorten plotting position. The relationship between the exceedance frequencies of peak inflows and peak outflows is not univocal, because the later is also influenced by the reservoir storage.

The expected annual damage (EAD) is one of the most frequently used measures in quantifying the costs related with flood events (Arnell, 1989) and can be expressed as (Eq. 10)

$\mathrm{EAD}=\sum_{u=1}^{W-1}\left(p_{u+1}-p_{u}\right) \times \frac{D_{u}+D_{u+1}}{2}$,

with $p_{u}$ being the non-exceedance frequency of the event ranked in the position $u$ and $D_{u}$ the value of the corresponding damage, where $W$ is the number of pairs \{ damage, probability $\}$ considered. The EAD concept was used in this study

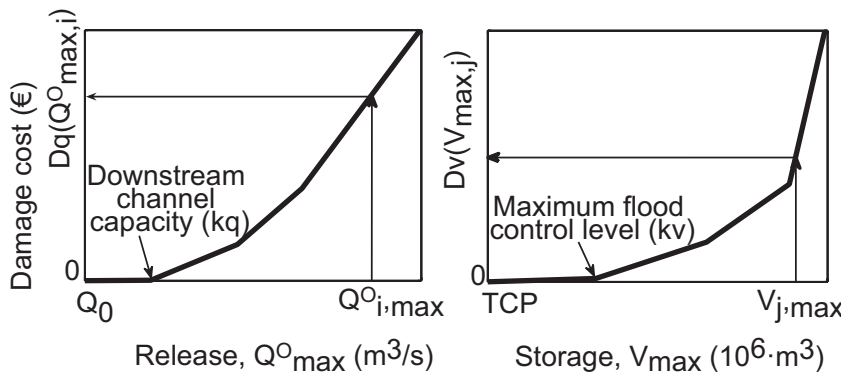

Fig. 4. Example of the relationship between damage and release (left) and damage and volume (right).

to determine the indicators $I q$ and $I v$, supposing that the probability of damage corresponds to that of the event that generated the damage (characterised in this case by $Q_{\max }^{\mathrm{O}}$ and $\left.V_{\max }\right)$. Accordingly, $I q$ was obtained (Eq. 11) by means of a probability weighted sum of the damage $D q$ associated with the maximum released flows.

$$
\begin{aligned}
I q & =\sum_{i=1}^{N-1}\left(F\left[Q_{\max , i+1}^{\mathrm{O}}\right]-F\left[Q_{\max , i}^{\mathrm{O}}\right]\right) \\
& \times D q\left(\frac{Q_{\max , i+1}^{\mathrm{O}}+Q_{\max , i}^{\mathrm{O}}}{2}\right)
\end{aligned}
$$

The index $i$ represents the position occupied in the ordered series of peak released flows. $p\left(Q_{\max }^{\mathrm{O}}\right)_{i}$ is the probability (Fig. 3) that the peak release $\left(Q_{\max }^{\mathrm{O}}\right)$ during flood abatement is found between $Q_{\max , i}^{\mathrm{O}}$ and $Q_{\max , i+1}^{\mathrm{O}}$. This probability of occurrence is constant (Eq. 12).

$$
\begin{aligned}
p\left(Q_{\max }^{\mathrm{O}}\right)_{i} & =p\left(Q_{\max , i}^{\mathrm{O}}<Q_{\max }^{\mathrm{O}}<Q_{\max , i+1}^{\mathrm{O}}\right) \\
& =\left(F\left[Q_{\max , i+1}\right]-F\left[Q_{\max , i}\right]\right)=\delta
\end{aligned}
$$

The damage $D q\left(Q_{\mathrm{max}, i}^{\mathrm{O}}\right)$ (Fig. 4) is null for values below a threshold $k q$, and hence $D q\left(Q_{\max , i}^{\mathrm{O}}\right)=0$, if $Q_{\max , i}^{\mathrm{O}} \leq k q$. This threshold is determined based on the downstream river characteristics (hydraulic capacity, land use, urban pressure, etc.).

Similarly, $I v$ was calculated in terms of the risk of damage $D v$ associated with the maximum volumes stored (Eq. 13).

$$
\begin{aligned}
I v= & \sum_{j=1}^{N-1}\left(F\left[V_{j+1, \max }\right]-F\left[V_{j, \max }\right]\right) \\
& \times D v\left(\frac{V_{j+1, \max }+V_{j, \max }}{2}\right)
\end{aligned}
$$

The variables $p\left(V_{\max }\right)_{j}$ and $D v\left(V_{\max , j}\right)$ have analogous meanings, though they refer to the maximum volume in the reservoir during the flood event, with a position in the distribution of maximum storage that is $j$. In such a case the damage is considered as negligible if $V_{\max , j} \leq k v . k v$ is derived 
from the dam-reservoir features and catchment characteristics upstream (conditioning the flood hydrographs that force the system).

It is important to highlight the difference between the risk of damage associated with discharge and levels or volumes. In the case of discharge the damage does indeed occur. However, reaching of a certain level in a reservoir during a flood event does not necessarily lead to dam failure; it implies risk of failure. Hence, the risk of damage (Eq. 14) associated with the volume determined as $D v\left(V_{\max , j}\right)$ is the result of the damage cost if a dam does fail (Cost break ), and the probability of failure conditioned to reach $V_{\max , j}$.

$$
D v\left(V_{\max , j}\right)=p\left(\operatorname{break} \mid V_{\max , j}\right) \cdot \text { Cost }_{\text {break }}
$$

The probability of failure $p\left(\operatorname{break} \mid V_{\max , j}\right)$ linked to a given storage $V_{\max , j}$ is the probability of reaching the volume at dam crest level $\left(V_{\mathrm{CDL}}\right)$, once $V_{\max , j}$ has been reached during a given event (Eq. 15).

$p\left(\operatorname{break} \mid V_{\max , j}\right)=p\left(V_{\max } \geq V_{\mathrm{CDL}} \mid V_{\max , j}\right)$

The probability to reach the level of dam failure, given that a certain level $V_{\max , j}$ has been reached during an event, is estimated by routing through the reservoir a large number of synthetic flood events with a medium to extremely high return period ( $T r=10$ to $200000 \mathrm{yr}$, approximately). Reservoir routing applied the Volumetric Evaluation Method (VEM), based, in turn, on operation rules (Girón et al., 2000). Assuming that dam overtopping leads to failure, $p\left(\right.$ break $\left.\mid V_{\max , j}\right)$ is calculated at each level reached from the simulation results by means of Eq. (16).

$p\left(\operatorname{break} \mid V_{\max , j}\right)=\frac{\text { No of floods in which } V_{\max } \geq V_{\mathrm{CDL}}}{\text { No of floods in which } V_{\max } \geq V_{\max , j}}$

The $p\left(\operatorname{break} \mid V_{\max , j}\right)$ function was estimated in that way in order to dissociate the definition of the damage function (due to reservoir storage) from the RFCM and its configurations analysed. This simplification may introduce some differences in the determination of the value of $p\left(\operatorname{break} \mid V_{\max , j}\right)$ for each particular case; however, for large floods this may have a slight impact on the results.

The damage variables (cost and risk) $D q$ and $D v$ are expressed in monetary terms (in euros). In the cases in which the damage cost function is unavailable or cannot be estimated, functions can be used that consider the risk (probability) of exceeding a given threshold without taking into account the consequences (Jain et al., 1992; Rasekh et al., 2010). In such a case, the PDA should be used.

An alternative option would be to involve definition of a risk indifference curve to replace the two functions examined above. Such a curve would be prepared by the respective dam authority and enable preferences and experience to be integrated into the reservoir operation. In addition, it would also reveal the two coordinates \{flow, volume \} that could mean equivalent damage or risk.
From among the aggregation methods the weighted sum is the chosen technique. As a function of synthesis the overall risk index $\operatorname{Ir}$ (Eq. 17) is proposed, which is equal to the sum of the released flow $(I q)$ and storage $(I v)$ risk indices.

$I r=I q+I v$

Here equal levels of priority or relevance are ascribed to both objective functions, as they are commensurable, expressed in the same currency (euros). Likewise, due to lack of supplementary information, it can be reasonably assumed that both aspects are equally relevant. The proper definition of these priorities may require participation of dam operators, in order to include their risk aversion and detailed knowledge about each particular reservoir system.

It should be noted that the label overall refers to the fact that the risks associated with both released flows and stored volume are grouped together.

The parameter set that provides the optimal value of $I r$ is named as balanced optimum solution $\left(S_{I r}\right)$, a term first proposed by Madsen $(2000,2003)$.

In addition, the calibration objective functions $I q$ and $I v$ allow the establishment of the Pareto front (PDA), in which each individual solution constitutes a compromise solution between the risk of damage downstream and risk of dam failure. The balanced solution is assessed in the context of the Pareto front.

\subsection{Reservoir flood control model}

The evaluation methodology presented should be considered as being separate from the RFCM used to manage the reservoir, because it can be applied to any parametric RFCM. In this study, a RFCM based on mixed integer linear programming (MILP) is used to represent the operation of the reservoir. The model is based on works performed by Windsor (1973) and Needham et al. (2000). The formulation of the RFCM can be found in the Appendix A.

The MILP optimisation problem applied for reservoir operation during one flood event involves the minimisation of an objective function that should not be confused with the objective function of the calibration methodology. Briefly, the objective function of the RFCM (OFRM) minimises the total penalty $(P)$ for a single flood. $P$ is obtained as the weighted sum of two penalty terms. One term is due to the released flows $\left(P Q^{\mathrm{O}}\right)$ and the second term is due to the stored volumes $(P V)$ during a flood event. The weights of the flow penalty and the storage penalty are, respectively, $w q$ and $w v$ (Eq. 18).

$\min _{Q^{\mathrm{O}, t ; V n, t}} P=w q \times P Q^{\mathrm{O}}+w v \times P V$

\subsection{Optimisation model parameterisation}

The parameterisation of the RFCM is explained in Appendix $\mathrm{B}$. The resulting calibration parameters are the following: the weight $w q$, the penalty corresponding to the flood 


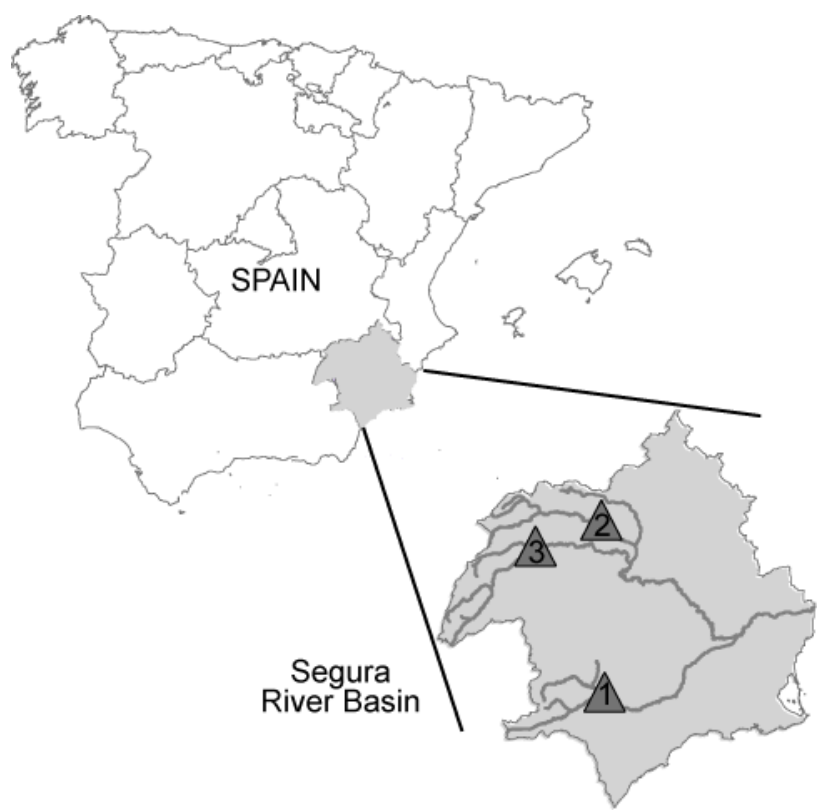

Fig. 5. Single reservoir systems analysed (case studies). Location map.

control level (PVfcl) and the exponent $(b)$ of the penalty function of the released flows.

The weight $w q$ and penalty PVfcl can take values in the range $[0,1]$. Although, in theory, $b$ can take any value, a range from one to six is analysed which assures that the minimum $I r$ corresponds to a value of $b$ included in the interval.

The function $I r=\psi(w q, \mathrm{PVfcl}, b)$ is therefore a hypersurface in the four-dimensional space that relates each triplet of parameters ( $w q, \mathrm{PVfcl}$ and $b)$ with a value of the overall risk index ( $I r)$. To characterise such hypersurface the RFCM is run for the flood ensemble and each combination of the three calibration parameters. The optimal parameter set is found through exploring the aforementioned hypersurface.

\section{Case studies}

The methodology was applied to three reservoirs located in the southeast of Spain, near the Mediterranean coast (Fig. 5). The three reservoirs have flood control among their main objectives and operate independently from each other. Therefore, each of them is considered as a single reservoir system. Main characteristics of each reservoir are included in Table 1.

The three catchments have semiarid climates with sudden intense storms typical of the Mediterranean region. These storms frequently cause flash floods.

The damage curves due to released flows (Fig. 6a, b and c) were estimated from the studies included in the technical data referring to potential impact at the dams. The damage curves associated with stored volume (Fig. 6d, e and f) were

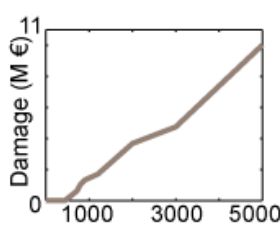

a)

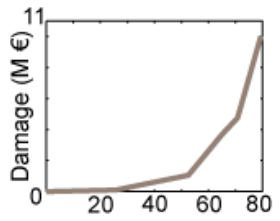

d)

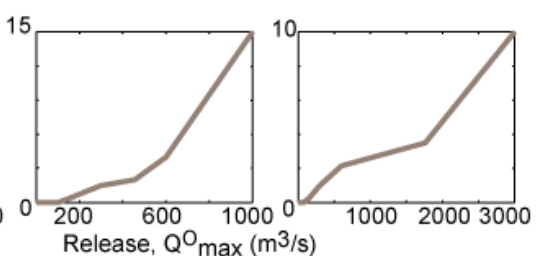

b)

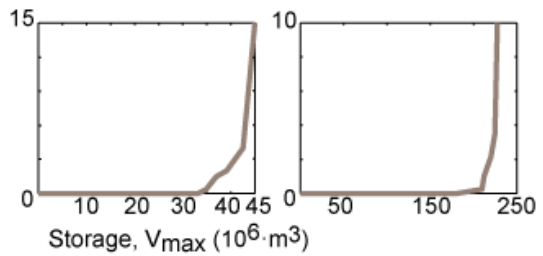

e) f)
Fig. 6. Damage vs. maximum release $(\mathbf{a}, \mathbf{b}, \mathbf{c})$ and damage vs. maximum volume stored (d, e, f), for the three case studies: Puentes (a, d), Talave (b, e), and Fuensanta (c, f).

calculated from the aforementioned data and through application of the methodology already described.

The reference values, $k q$ and $k v$, for the calculation of $I r$ correspond to the flow alert (maximum downstream channel capacity, MCC) and the flood control level (FCL), respectively. The damage cost below these thresholds is considered as negligible. The levels (or volumes) and characteristic flows considered here as singular values are featured in $\mathrm{Ta}$ ble 2 .

The initial level of a reservoir is a state variable of stochastic nature, with the corresponding value having significant influence on the impact of the operation of the infrastructure. However, with the aim of simplifying the case studies, the initial level was considered equal to the maximum level (the top of conservation pool, TCP) that could be reached during the ordinary operating conditions (prior to a flood event) for all events. Such consideration is a practice commonly implemented in dam design (Carvajal et al., 2009). Finally, for each case study, ensembles of 1000 flash flood events were generated, with a hyetograph duration varying from one half of the time of concentration $(t c)$ to three times $t c$ for the respective basins.

\section{Results and discussion}

The hypersurface acquired during the calibration process is shown in Fig. 7 through the contour curves of equal value of Ir , corresponding to cross sections performed in accordance with the selected values of the parameter PVfcl for each case study. The risk associated with release is, in general, appreciably greater than that connected with dam safety, particularly in Puentes and Fuensanta. This agrees with the fact that the optimal values of $w q$ are, in the majority of cases, greater 
Table 1. Case studies: Characteristics of the reservoirs and respective catchments.

\begin{tabular}{lrrrrrr}
\hline Dam & $\begin{array}{r}\text { Catchment } \\
\text { area } \\
\left(\mathrm{km}^{2}\right)\end{array}$ & $\begin{array}{r}100-\mathrm{yr} \\
\text { flood peak } \\
\left(\mathrm{m}^{3} \mathrm{~s}^{-1}\right)\end{array}$ & $\begin{array}{r}\text { Volume of the } \\
100-\mathrm{yr} \text { flood } \\
\left(10^{6} \mathrm{~m}^{3}\right)\end{array}$ & $\begin{array}{r}\text { Downstream } \\
\text { channel capacity } \\
\left(\mathrm{m}^{3} \mathrm{~s}^{-1}\right)\end{array}$ & $\begin{array}{r}\text { Max. flood } \\
\text { control level } \\
\left(10^{6} \mathrm{~m}^{3}\right)\end{array}$ & $\begin{array}{r}\text { Flood } \\
\text { control pool } \\
\left(10^{6} \mathrm{~m}^{3}\right)\end{array}$ \\
\hline Puentes & 1388 & 1510 & 71 & 440 & 25.8 & 12.4 \\
Talave & 767 & 558 & 55 & 100 & 34.8 & 2.9 \\
Fuensanta & 1221 & 686 & 38 & 75 & 209.7 & 30.8 \\
\hline
\end{tabular}

Table 2. Abbreviations used to refer to flows and volume (levels), which are characteristic of the reservoir and the catchment.

\begin{tabular}{llrrr}
\hline Symbol & Description & Puentes & Fuensanta & Talave \\
\hline TCP & Top of conservation pool & 460 & 595.75 & 508.9 \\
FCL & Flood control level (top of flood control pool) & 464 & 599.45 & 509.9 \\
DFL & Design flood level & 470 & 601.1 & 511.3 \\
CDL & Crest dam level & 474 & 601.4 & 512.4 \\
MCC & Maximum downstream channel capacity & 440 & 75 & 100 \\
WF & Warning flow (mild damage flow) & 800 & 150 & 150 \\
EF & Emergency flow (moderate damage flow) & 2000 & 300 & 300 \\
\hline
\end{tabular}

than 0.5 (reaching one in the case of the above mentioned dams).

When the parameter $w q$ takes value one, $w v$ is zero. In such a case, the OFRM and, hence, the management of the reservoir depend solely on the released flow. This would suggest that for the range of hydrologic loads considered, the probability of topping a given critical level is extremely low compared with the probability of exceeding a critical flow.

The storage penalty term (Eq. 18) for $V_{t}=\mathrm{FCL}$ is $w v P V_{t}=w v \mathrm{PVfcl}$. Although the optimal values of $\mathrm{PVfcl}$ differ from one case study to another, the value of the storage penalty term for all the cases are located in the range of $0.05-$ 0.15 . Such a modest penalty allows the FCL to be reached, given that it implies a lesser risk than that corresponding to the flow that would be released, should the constraint not be relaxed.

Across the cases it is observed that for values $w q$ greater than the optimum for each value of $\mathrm{pVfcl}$, the gradient surface increases markedly, whereas for lower values the surface shows a smoother slope. In the case of the Puentes dam, in the region comprising the values of $w q$ and $b$, lower and greater than their respective optima, for each PVfcl the objective function loses sensitivity with regard to $b$ (Fig. 7a).

At Talave, for PVfcl greater than or equal to the optimum, and for values of $w q$ lower than the optimum of each case, the function becomes insensitive to $b$ (Fig. 7b). The cross section $\mathrm{PVfcl}=0.1$, for this case, is an exception with a significant variation in all directions and becomes distanced from the optimum.

At Fuensanta (Fig. 7c), around $10 \%$ of the flood events analysed exceed the FCL (the threshold volume), with the remaining inflows being stored in the abatement volume without release and, therefore, without jeopardising the safety of the dam. This justifies the value of $w q$ as being close to one; in addition to a value of $b=1.5$. Lower values of $b$ penalise the flows that are lower than the peak inflow more severely than higher values of $b$. In another sense, values of $b$ lower than 1.5 (optimal) involve a significant increase in risk, due to release leading to a considerable increase in the risk indicator $(I r)$. The traits of the Fuensanta dam could justify the fact that the optimum values of $w q$ and $b$ are maintained as practically constant across a wide range of $\mathrm{PVfcl}$. In this case the summary function is highly insensitive to the parameter. For values of $\mathrm{PVfcl}$ around optimum and values of $w q$ lower than 0.6 , the function loses some degree of sensitivity with regard to $b$ (Fig. 7c).

From the results obtained it is deduced that the most prominent parameter in the model is the weight of the term of the penalty of flows in the objective function $w q$, or alternatively, the weight of the term of volume $w v$.

In Fig. 8, the behavioural patterns that involve each of the configurations in the exceedance probability distribution curves of the maximum flow discharged and of the maximum volume in the reservoir are analysed. For the Talave and Fuensanta dams, it is noted that the probability distribution of the volumes corresponding to $S_{I r}$ offers one of the largest areas to the left of the threshold. However, this does not have particular influence given that to the right of the threshold the associated area is small in relation to the other configurations.

The optimum solution seeks to minimise the areas (weighted by the damage) under the probability curves to the right of the thresholds $k q$ and $k v$. As the area is weighted by the damage, it is not only of interest to obtain a smaller area but also to assure that it is concentrated as close as is possible to the threshold. Thus, the optimal solution is that which 

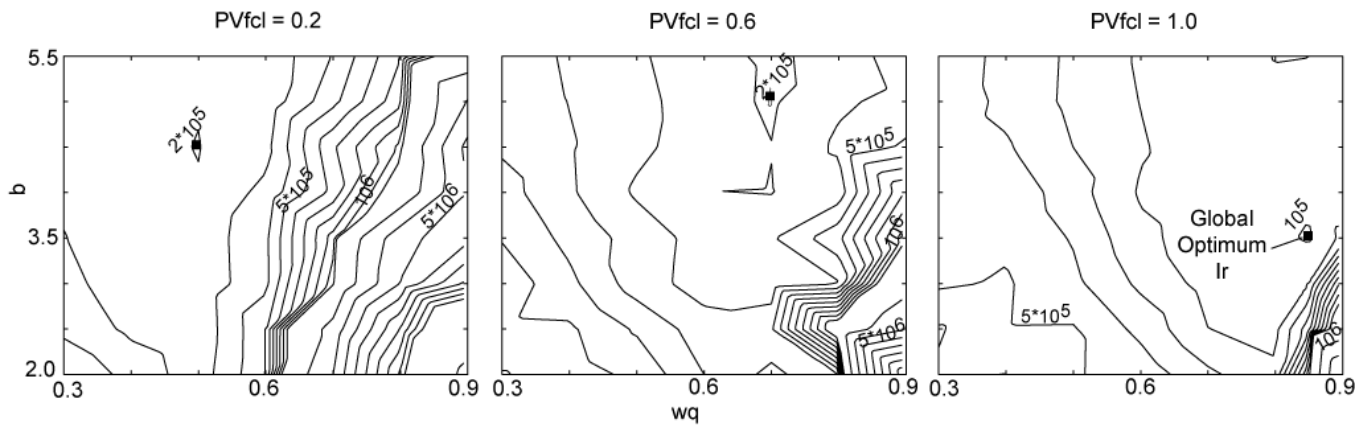

a)
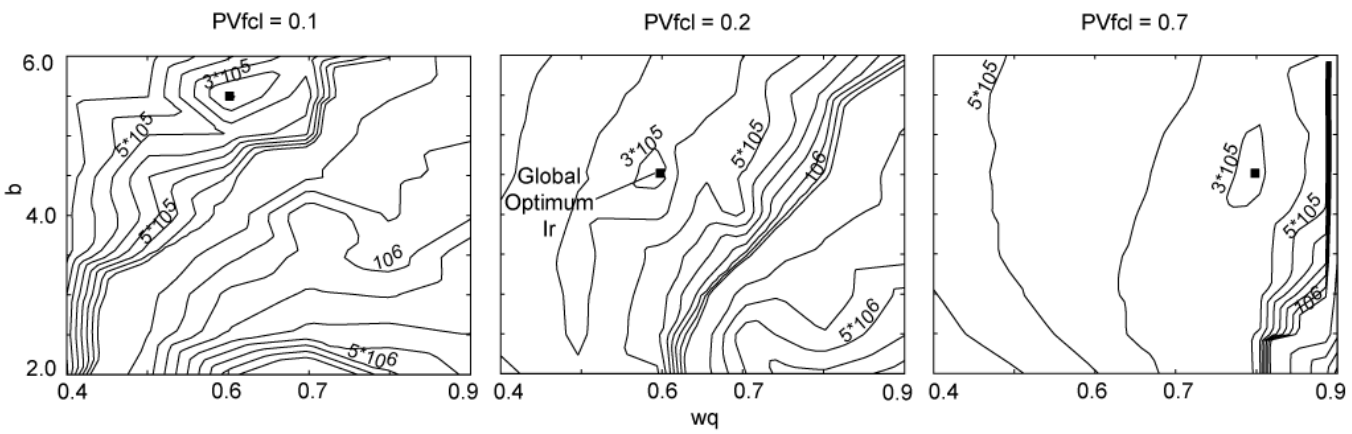

b)
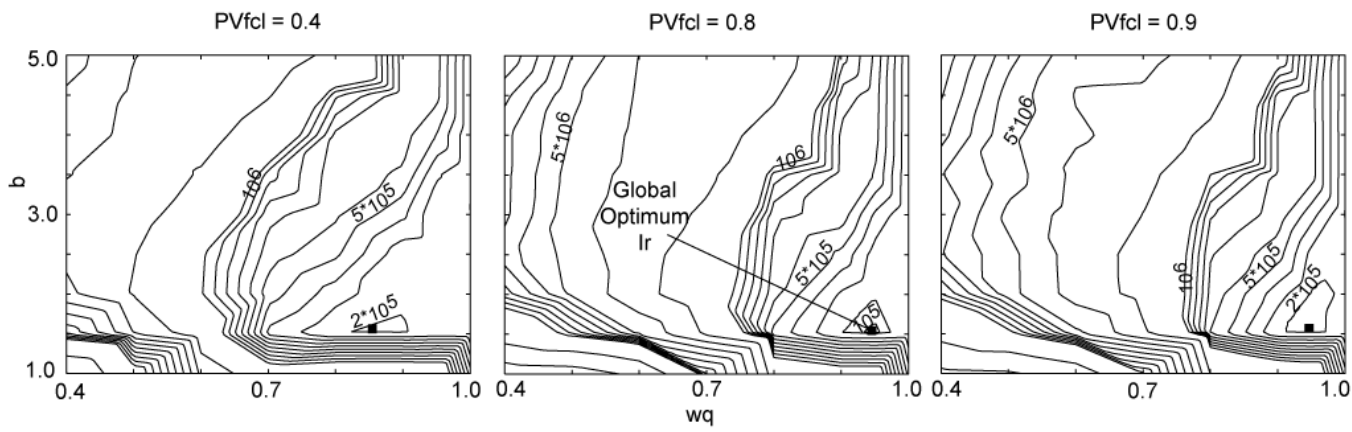

c)

Fig. 7. Results of the simulations: values in $\operatorname{Ir}(€)$ for the various configurations analysed. The minimum $\operatorname{Ir}$ (black box) is shown for each selected value of PVfcl. The general optimum value of $I r$ is labelled for each case study: (a) Puentes Dam; (b) Talave Dam; and (c) Fuensanta Dam.

includes these two conditions for each variable in a simultaneous way.

In another sense, on numerous occasions it is observed that in the probability distributions corresponding to $S_{I r} \max -$ imum flows or volumes lower than in other solutions are reached. One such example is found at the Fuensanta reservoir where the maximum flow reached with the optimal solution is around $600 \mathrm{~m}^{3} \mathrm{~s}^{-1}$, while strategies for those that reach $900 \mathrm{~m}^{3} \mathrm{~s}^{-1}$ are also observed. Likewise, concerning the levels (or volumes) corresponding to $S_{I r}$, the DFL is not reached, while other solutions exceed it and near the crest level. Furthermore, at Talave the maximum level corresponding to $S_{I r}$ is slightly higher than FCL, while for a significant number of parameters sets the DFL is exceeded, even reaching the dam crest.
Such an example is shown at the Puentes reservoir, where the probability distributions corresponding to two other parameter sets (A and B) are indicated in Fig. 9a. It is noticeable that they are slightly better than the balanced solution $\left(S_{I r}\right)$ in one of the two criteria, though clearly worse for the other criterion.

It is observed (Fig. 9b) that when faced with the same flood event, the RFCM with the optimal parameter set allows management of the reservoir to avoid damage being produced downstream (the peak flow released in the region of the MCC), though the safety of the dam is not jeopardised either (the maximum reached is slightly less than the FCL). In solution (A), flows are released that cause light-to-moderate damage downstream (the peak flow released is around 1.5 times the MCC), whereas the level in the reservoir scarcely 

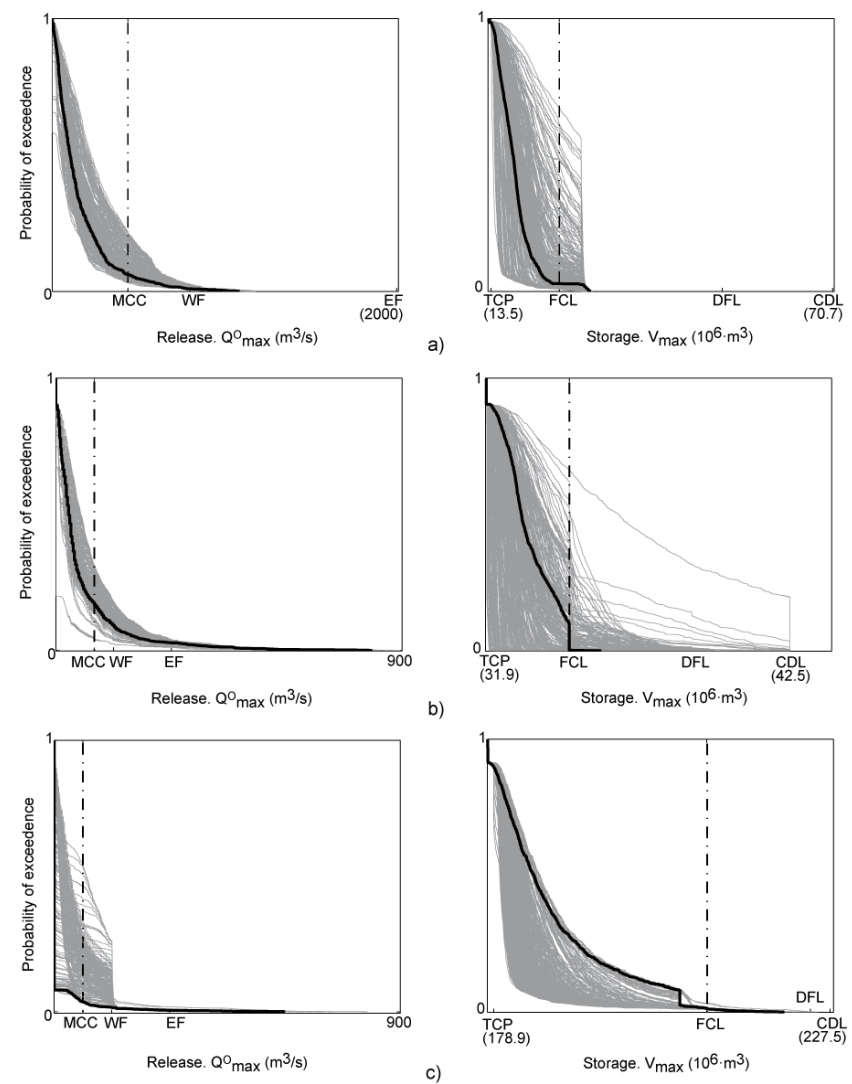

Fig. 8. Probability distribution of maximum release (left column) and maximum storage (right column) for: (a) Puentes Dam, (b) Talave Dam, and (c) Fuensanta Dam. The optimal solution (black line) and the reference values ( $k q$ and $k v$, dashed line) are shown.

Table 3. Results of the calibration process, using the aggregated approach, represented by $I r$.

\begin{tabular}{lrrrr}
\hline \multirow{2}{*}{ Dam } & Global risk index, Ir & \multicolumn{4}{c}{ Optimal parameters } \\
\cline { 2 - 5 } & $\left(10^{3}\right.$ euros $)$ & $w q$ & $P V f c l$ & $b$ \\
\hline Puentes & 98.7 & 0.85 & 1.00 & 3.50 \\
Talave & 232.4 & 0.60 & 0.20 & 4.50 \\
Fuensanta & 84.7 & 0.95 & 0.80 & 1.50 \\
\hline
\end{tabular}

varies in terms of its initial value (TCP). Conversely, in solution (B) the peak flow released is approximately $25 \%$ less than the corresponding threshold (MCC), though the level in the reservoir exceeds the FCL.

The overall risk index, $I r$, allowed the study to synthesise a single behavioural value of the parameter set with reference to two relevant aspects in the abatement of the entire flash flood ensemble. By means of such an index the functioning of each parameter set was compared to each other, understanding the most suitable to be that which had a lower value of $I r$. Table 3 summarises the results obtained in the parameter calibration by means of APA.

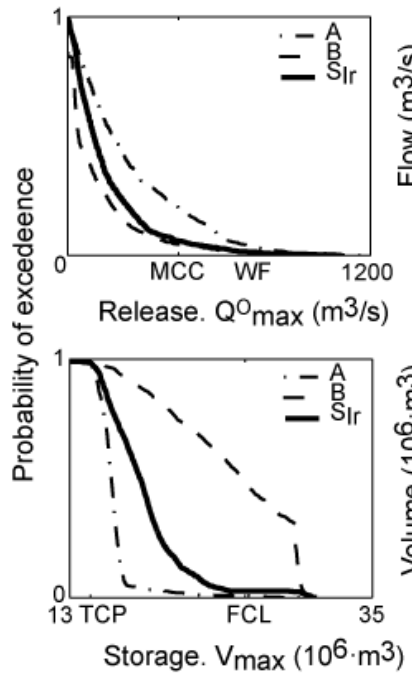

a)
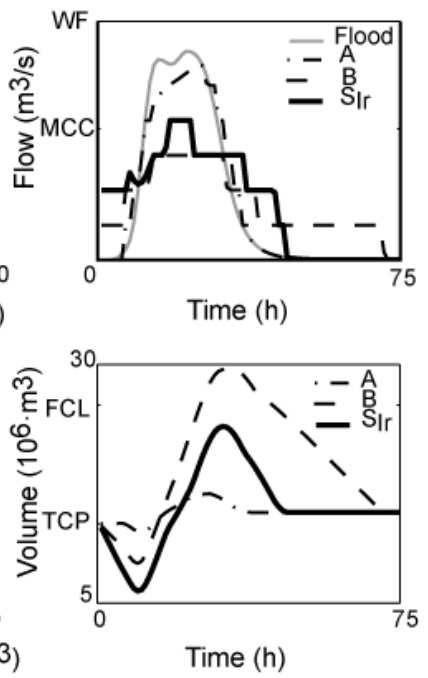

b)
Fig. 9. Example of results for different parameter sets (A, B and $S_{I r}$ ) and their bearing in the Puentes case: (a) probability distribution of the maximum volume released and maximum stored; (b) operation of the dam-reservoir for a given hydrograph. $S_{I r}$ shows the aptest balance between the two objectives of flood control.

In absolute terms, the results show that the Fuensanta and Puentes dams manage the floods analysed with a damage cost lower than that of the Talave dam. The reason for this, considering the abatement volume available at the Talave dam, is that for a significant range of floods, the dam releases flows that exceed the damage threshold downstream. The flood inflow at each reservoir, although it does have a certain magnitude with regard to their drainage catchment, has been generated by maintaining certain analogous characteristics in terms of the range of duration of storm events $(1 / 2 t c$ to three $t c)$ and of return periods ( $T r=1$ up to around $1000 \mathrm{yr}$ ).

The calibration proposed here transformed a multiobjective problem into one of a single-objective through the aggregation of evaluation criteria (weighted sum). This was possible due to commensurable criteria measured in the same currency unit (euros). The two criteria used measure the risk (the product of the probability that an event occurs and its consequences) that implicates reservoir management, one with regard to the safety of the dam (Iv) and another with regard to the downstream impact $(I q)$. Given their equal relevance, the aspects were assigned an equal weight.

With the purpose of evaluating the behaviour of the proposed calibration methodology from a multiobjective perspective, the Pareto front was determined. The nondominated solutions emerged from the trade-off between the objective functions $I q$ and $I v$ (Fig. 10). The Pareto solutions were established through use of the procedure offered by Wagener et al. (2001). Among the solutions that consti- 

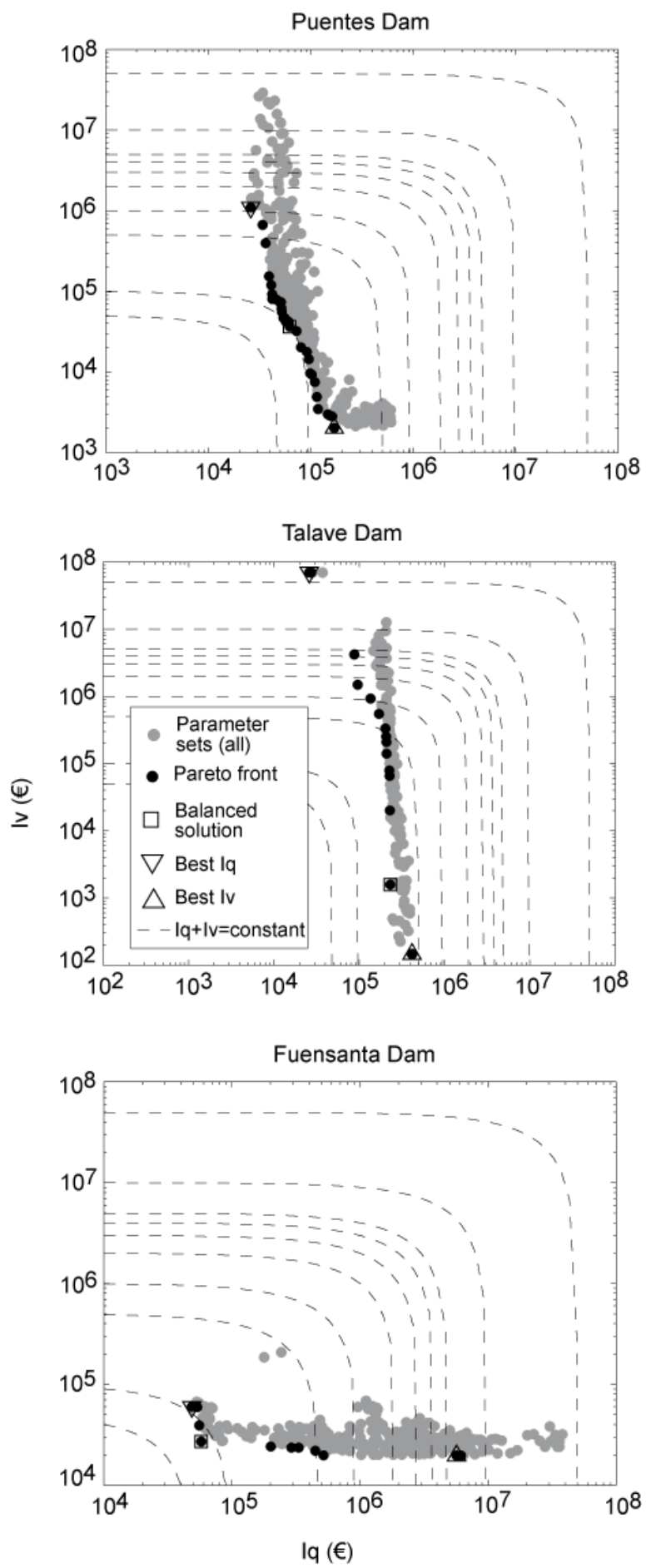

Fig. 10. Behavioural criteria values corresponding to the parameter sets analysed (grey dots) for the three case studies. The black points correspond to the Pareto front. The square and triangular symbols indicate, respectively, the balanced optimum solution and the best solutions for each of the two objectives.
Table 4. Range of objective functions ( $I q$ and $I v)$ values for the Pareto solutions.

\begin{tabular}{lcc}
\hline \multirow{2}{*}{ Dam } & \multicolumn{2}{c}{ Objective functions range [euros] } \\
\cline { 2 - 3 } & \multicolumn{1}{c}{$I q$} & $I v$ \\
\hline Puentes & $2.59 \times 10^{4}-1.70 \times 10^{5}$ & $2.02 \times 10^{3}-1.10 \times 10^{6}$ \\
Talave & $2.60 \times 10^{4}-2.31 \times 10^{5}$ & $1.58 \times 10^{3}-6.98 \times 10^{7}$ \\
Fuensanta & $4.86 \times 10^{4}-5.67 \times 10^{6}$ & $1.97 \times 10^{4}-6.00 \times 10^{4}$ \\
\hline
\end{tabular}

tute the Pareto front, the balanced solution corresponds to that which minimises the distance from origin.

The Talave reservoir offers a significant variation with regard to $I v$, though relatively little to $I q$. The calibration based only on flows (optimum $I q$ ) involves a high degree of risk to the safety of the dam. However, the minimum $I v$ entails an increased risk through flows of one order of magnitude, being maintained at moderate values. Therefore, at this dam the point corresponding to $S_{I r}$ is located relatively near to the optimum $I v$. The Puentes reservoir, in which the gradient of the front is less steep, (the values of $I r$ correspond to the optimum $I q$ and the optimum $I v$ show less difference in order of magnitude), the balanced solution is displaced towards the central area.

Contrary to the Talave reservoir, for the Fuensanta case a small relaxation in volume (IV) offers a sizeable improvement in flows. For this reason the balanced optimum nears optimum $I q$. Although the solutions are situated along a practically horizontal strip, the Pareto front presents a slight $L$-shape, with the balanced solution coinciding with the vertex of the $L$.

In the three case studies, $S_{I r}$ corresponds to a break point on the Pareto front. It implies that moving away from the optimum (along the Pareto front) one objective improves slightly though worsening the other considerably. Such a solution provides an adequate compromise between the two objectives, leading to risk values of a moderate nature both in the case of damage downstream and in that of dam safety.

The ranges of the objective function values corresponding to the Pareto solutions are summarised in Table 4.

Figure 11 shows the variation in the optimal parameter set throughout the Pareto front. The parameter values are standardised with regard to their ranges, in such a way that the lower and greater limits of the ranges are, respectively, 0 and 1. These results are summarised in Table 5.

A substantial degree of variability in the parameter values is noted throughout the non-inferior solutions. In the three cases studies, the parameter $w q$ reveals a degree of variability that is lower than that of the two parameters, which would underline its relevance in the general behaviour of the model (Madsen, 2003). The results show a general falling tendency of the weight $w q$ as more relevance is given to the risk associated with the stored volume (a lower $I v$ and greater $I q$ ), especially at Puentes and Talave. That is to say, for a growing 
Table 5. Range of parameter values for all the parameter sets evaluated and non-dominated solutions; and parameter values corresponding to the balanced optimum solution.

\begin{tabular}{lrrrrrrrrr}
\hline \multirow{2}{*}{ Dam } & \multicolumn{3}{c}{ Initial parameter range } & \multicolumn{3}{c}{ Pareto solutions range } & \multicolumn{3}{c}{ Balanced optimum } \\
\cline { 2 - 10 } & $w q$ & PVfcl & $b$ & $w q$ & PVfcl & $b$ & $w q$ & PVfcl & $b$ \\
\hline Puentes & $0.3-1.0$ & $0.2-0.1$ & $2.0-5.5$ & $0.5-0.95$ & $0.4-1.0$ & $3.0-5.5$ & 0.85 & 1.00 & 3.50 \\
Talave & $0.2-1.0$ & $0.1-0.9$ & $2.0-6.0$ & $0.7-1.0$ & $0.2-0.7$ & $2.0-5.5$ & 0.60 & 0.20 & 4.50 \\
Fuensanta & $0.4-1.0$ & $0.3-0.9$ & $1.0-5.0$ & $0.4-1.0$ & $0.4-0.9$ & $1.5-4.0$ & 0.95 & 0.80 & 1.50 \\
\hline
\end{tabular}
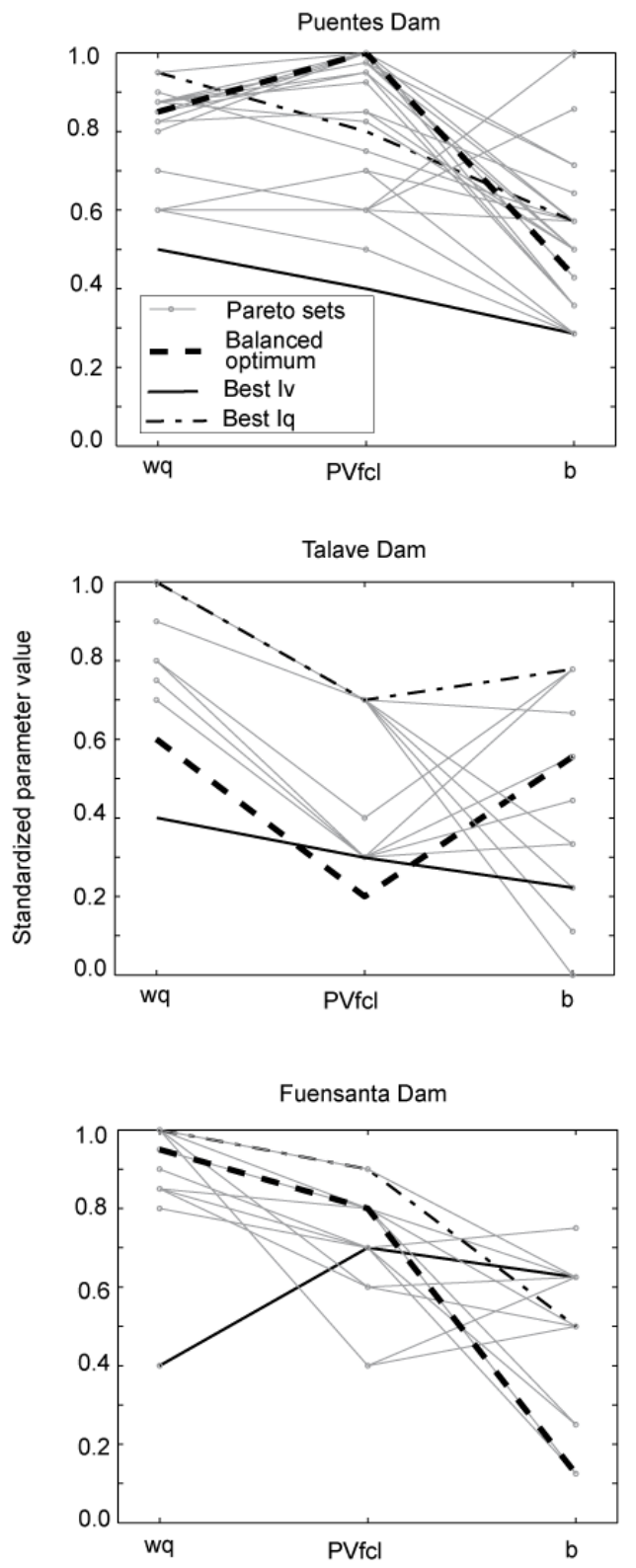

Fig. 11. Standardised range of the parameter values corresponding to the Pareto solutions. The balanced optimum solution is shown by a thick-dashed line. significance of the objective associated with dam safety during the calibration process, the weight of the term of the volume in the objective function in reservoir operation also increases. In the case of the Fuensanta dam, given the large volume of flood abatement in relation to the volume of flood events, the risk is relatively lower and little sensitive to the reservoir operation, which suggests that the previously mentioned effect is less marked.

The balanced optimum solution derived from the overall risk index facilitates an appropriate solution for both objectives. It avoids not only the additional computational cost that entails resorting to the Pareto front, but also the ensuing analysis required to select the parameter set to be implemented in the case of a given set of floods.

\section{Conclusions}

RFCMs serve as potentially efficient tools in providing help to decision making in the management of dams in the case of a flood event. Correct formulation of the model and its parameters is paramount, with their adequacy being of importance not only for a given flood event but also across an important spectrum of hydrologic loads.

This work has developed a general probabilistic methodology for evaluating parametric RFCMs from a multiobjective perspective. It was done through the synthesis of the behaviour of the model under a representative flood hydrograph ensemble in a single numeric value. To perform this, the use of the overall risk index $I r$ has been proposed. This index represents the expected damage cost associated both with the impact downstream due to released flow and the impact on the dam as a result of the levels (or volumes) reached for the flood ensemble. The parameter set that corresponds to a lower value of $I r$ was considered as the most satisfactory. It was termed the balanced optimum solution given the equal relevance assigned to each flood abatement objective: the aforementioned twofold aim of minimising damage to the downstream areas and safeguarding the dam.

The calibrated RFCM provided, at each of the three case studies, maximum levels and peak flows released that together involved a lower damage cost than those corresponding to the non-calibrated model. 
The comparative analysis of the balanced optimum solution with others belonging to the Pareto front showed, in the three cases, that it serves as a sound compromise between the two objectives. The use of the Pareto dominance approach to calibrate the model facilitates analysis of the uncertainty related with the problem considered. However, if the selection of one optimum parameter set is to be undertaken, the use of the aggregated objective function (balanced optimum) avoids the requirement of defining an additional procedure to select one solution among those belonging to the Pareto front. Consequently, computational time effort is reduced. Furthermore, definition of such an additional criterion requires the expertise pertaining to the particular case studied. The behavioural adequacy of the balanced optimum solution, with regard to the remaining Pareto solutions, was also shown by Madsen $(2000,2003)$ for the calibration of hydrologic models (MIKE 11/NAM and MIKE SHE), and by Ngo et al. (2007) for the optimisation of reservoir operating strategies.

One determining factor in the evaluation of the methodology proposed lies in the difficulty linked with the correct establishment of the damage curve. To perform this to an acceptable standard, it would be advisable to draw on the collaboration of the respective dam management authorities. An additional arguable limitation would concern sole evaluation of the maximum flows released and maximum volumes, without taking into consideration either the evolution of the hydrographs and levels or the gradients related with them.

New research, in which a greater number of case studies are included, is necessary for establishing a pattern or norm in the relationship among the parameters values of the RFCM used and the characteristics of reservoirs.

An important aspect to introduce in the analysis would be the impact of the initial water level on the model and on the optimal parameter set. This will require use of the distribution function of initial levels and Monte Carlo techniques. In addition, real time operation of the calibrated RFCM model should be evaluated.

\section{Appendix A}

\section{Reservoir flood control model (RFCM)}

In this work the reservoir operation was implemented through an optimisation model (MILP), based on mixed integer linear programming similar to those proposed by Windsor (1973) and Needham et al. (2000).

The objective function (Eq. A1) of the MILP model used in this work entails minimisation of the weighted sum of the two penalty terms $(P)$ : one due to released flows and the other to volume (or level) reached in the reservoir. The involved parameters and variables are defined in Table A1. The penalty values of the OFRM are captured from the respective penalty functions. The weights $w q$ and $w v$ are complementary, by which the sum total is equal to the unit.
Table A1. Meaning of the variables $(v)$, indices $(i)$ and parameters $(p)$ of the OFRM.

\begin{tabular}{ll}
\hline Symbol & Description \\
\hline$w q$ & Weight of released flow term $(p)$ \\
$w v$ & Weight of storage term $(p)$ \\
$Q^{\mathrm{O}_{t}^{m}}$ & Released flow for interval $t$ and segment $m(v)$ \\
$V t^{s}$ & Storage for interval $t$ and segment $s(v)$ \\
$P Q_{t}^{\mathrm{O}}$ & Release penalty $(v)$ \\
$P V_{t}$ & Storage penalty $(v)$ \\
$\mathrm{d} t$ & Time step $(p)$ \\
$t$ & Time index $(i)$ \\
$T$ & Time horizon $(p)$ \\
$m$ & Release penalty curve segment index $(i)$ \\
$s$ & Storage penalty curve segment index $(i)$ \\
$M$ & Number of segments of release penalty curve $(p)$ \\
$S$ & Number of segments of storage penalty curve $(p)$ \\
$\beta_{m}^{q}$ & Slope of release penalty curve segment $m(p)$ \\
$\beta_{s}^{v}$ & Slope of storage penalty curve segment $s(p)$ \\
$V_{0}$ & Initial vertex of storage penalty curve $(p)$ \\
$P V_{0}$ & Penalty corresponding to $V_{0}(p)$ \\
\hline
\end{tabular}

$$
\begin{aligned}
P & =w q \sum_{t=1}^{T / \mathrm{d} t} P Q_{t}^{\mathrm{O}}+w v \sum_{t=1}^{T / \mathrm{d} t} P V_{t} \\
& =w q \sum_{t=1}^{T / \mathrm{d} t} \sum_{m=1}^{M} \beta_{m}^{q} Q_{t}^{\mathrm{O}^{m}}+w v \sum_{t=1}^{T / \mathrm{d} t} \sum_{s=1}^{S}\left(P V_{0}+\beta_{s}^{v} V_{t}^{s}\right)
\end{aligned}
$$

In order to simplify the notation, the subscript $n$ has been eliminated (that identifies the sample to which it belongs) of the released flow $Q_{n, t}^{\mathrm{O}}$ and stored volume $V_{n, t}$ variables. The OFRM is evaluated individually for each flood event.

The model constraints involve hydraulic and operational aspects. Some of them are the maximum and minimum reservoir levels, and the maximum and minimum volume that the outlets and spillways can manage.

On the one hand, the main advantages of linear programming models are the simplicity and flexibility with which they can be adapted to diverse cases with minimal change (in addition to the assurance that the optimum reached is the global optimum). On the other, they do encounter the disadvantage that all the relations involved (OF and constraints) are required to be linear or linearisable (Rani and Moreira, 2010; Labadie, 2004).

The inclusion of soft constraints through penalty functions allows operation rules of an essentially linguistic nature to be included in the mathematical model, which reduces the gap between the theoretical development of optimisation models and practical application (Chang, 2008). 


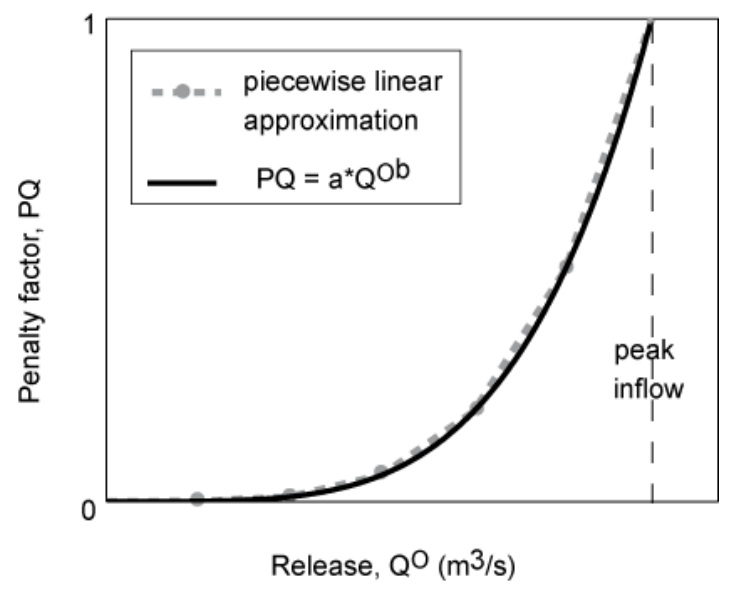

Fig. B1. Example of the released flow penalty curve (solid line) and piecewise linear approximation (dotted line).

\section{Appendix B}

\section{Parameterisation of the RFCM}

The constraint and penalty functions of the RFCM were linearised by means of piecewise linear approximations. According to the formulation of the RFCM, the number of parameters to be defined in the model is $8+M+S$. In order to reduce the number of parameters to be defined, the penalty function of released flow $P Q^{\mathrm{O}}$ (Fig. B1), was approximated by a potential function (Eq. B1) of exponent $b$, where the coefficient $a$ is such that the penalty for a value of peak flow released equal to the peak inflow point is one (the penalty of flow curve varies with the flood event considered). The exponent $b$ is a parameter of the penalty function. For the same flood event, the lower is $b$, the higher is the penalty assigned to the set of flows.

$P Q^{\mathrm{O}}=a Q^{\mathrm{O}^{b}}$

Hence, the penalty function of volume released is defined automatically for each flood event, reducing to two the number of parameters necessary ( $b$ and $M$ ) and leading to the release of lower flow than the inflow maximums. The value of $M$ was assumed to be equal to six, as indicated by a prior sensitivity analysis.

The penalty function of the volume stored was defined as a 5 segments piecewise linear function (Fig. B2). In this way, both the high and extremely low volumes were strongly penalised, with a minimum penalty (zero) corresponding to the volume at the top of the conservation pool (TCP), and this being the volume at which the abatement should end. Another singular point of the curve is that corresponding to the volume at flood control level (FCL), which has a penalty that can vary, a priori, between minimum and maximum. The volume at the crest dam level (CDL) has a maximum penalty (equal to one). The volume $V_{0}$ corresponds to the first vertex

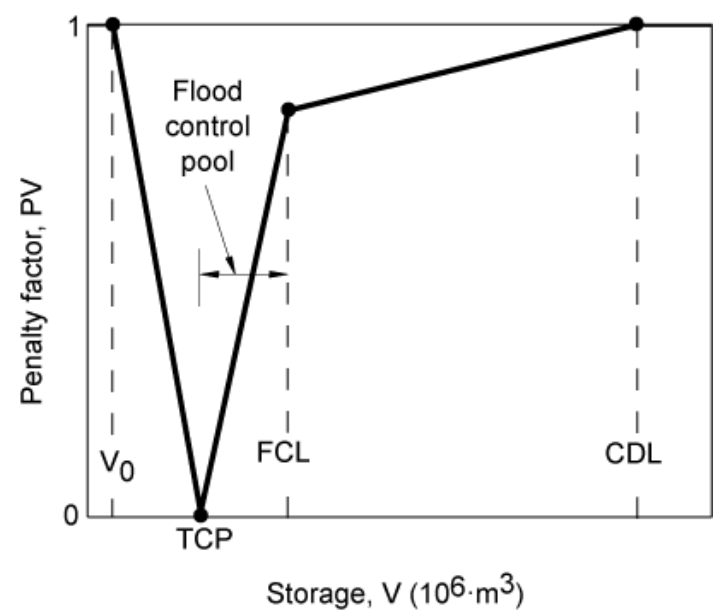

Fig. B2. Example of the storage penalty curve.

of the curve and the penalty $P V_{0}$ is assumed as equal to one. The volumes lower than $V_{0}$ have a penalty equal to one. Accordingly, the number of values necessary to be established beforehand is reduced from $S+1$ to two ( $\mathrm{PVfcl}$ and $V_{0}$ ).

\section{Appendix C}

\section{Notation}

$\begin{array}{ll}\text { RFCM } & \text { Abbreviation for reservoir flood control model } \\ \pi & \text { Transfer function (reservoir operation model) } \\ U & \text { Input of model } \pi \\ Y & \text { Output of model } \pi \\ Q^{\mathrm{I}}(t) & \text { Inflow (flood), as a function of time } \\ Q^{\mathrm{O}}(t) & \text { Outflow (released flow), as a function of time } \\ V(t) & \text { Stored volume in the reservoir (storage), as a function } \\ & \text { of time } \\ V\left(t_{0}\right) & \text { Initial storage (reservoir initial state) } \\ t & \text { Time interval (time index) } \\ t_{0} & \text { Initial interval } \\ \theta & \text { Parameters set (vector of } R \text { elements) } \\ R & \text { Number of model parameters } \\ T & \text { Time horizon (maximum flood duration) } \\ N & \text { Number of events in the flood ensemble } \\ n & n \text {-th event in the flood ensemble } \\ F[.] & \text { Cumulative distribution function of a random variable } \\ p(.) & \text { Probability of occurrence } \\ \omega_{k} & k \text {-th characterisation variable } \\ \varphi_{k} & \left.k \text {-th characterisation operator (to determine } \omega_{k}\right), \text { in this } \\ K & \text { study } \varphi_{k}=\text { max(.) } \\ \omega_{k}^{n} & \text { Total number of characterisation variables } \\ \Psi & \text { Value of } \omega_{k} \text { for the } n \text {-th flood } \\ & \text { Summary function to synthesise the characterisation } \\ & \text { variables } \omega_{k}\end{array}$




\begin{tabular}{|c|c|}
\hline$\theta_{g}$ & $\begin{array}{l}\text { One particular set of parameters, among feasible } \\
\text { parameter combinations (vector of } R \text { elements) }\end{array}$ \\
\hline$g$ & Parameter set index \\
\hline$G$ & Total number of parameter sets analysed \\
\hline$I_{g}$ & Result of $\Psi$ applied to $\theta_{g}$ (scalar) \\
\hline PDA & Pareto dominance approach \\
\hline APA & Aggregated approach \\
\hline $\mathbf{Q}^{\mathrm{I}} n, t$ & Inflow matrix $(N \times T$ elements $)$ \\
\hline $\mathbf{Q}^{\mathrm{O}} n, t$ & Outflow matrix $(N \times T$ elements $)$ \\
\hline $\mathbf{V} n, t$ & Storage matrix $(N \times T$ elements $)$ \\
\hline $\boldsymbol{V} n, 0$ & Initial storage vector ( $N$ elements) \\
\hline$Q_{\max }^{\mathrm{O}}$ & Peak released flows (vector of $N$ elements) \\
\hline$Q_{\max , n}^{\mathrm{O}}$ & $\begin{array}{l}\text { Peak released flow for the } n \text {-th flood of the en- } \\
\text { semble }\end{array}$ \\
\hline$Q_{\max , i}^{\mathrm{O}}$ & $\begin{array}{l}\text { Peak released flow for the } i \text {-th event of the peak } \\
\text { released flows ordered series }\end{array}$ \\
\hline$V_{\max }$ & $\begin{array}{l}\text { Maximum stored volumes (vector for } N \text { ele- } \\
\text { ments) }\end{array}$ \\
\hline$V_{\max , n}$ & $\begin{array}{l}\text { Maximum storage for the } n \text {-th flood of the en- } \\
\text { semble }\end{array}$ \\
\hline$V_{\max , j}$ & $\begin{array}{l}\text { Maximum storage for the } j \text {-th event of the maxi- } \\
\text { mum storage ordered series }\end{array}$ \\
\hline$i, j$ & $\begin{array}{l}\text { Position occupied by } Q_{i \text {,max }}^{\mathrm{O}} \text { or } V_{j . \max } \text {, respec- } \\
\text { tively, in the corresponding ordered series }\end{array}$ \\
\hline$Q_{\max }^{\mathrm{O}}$ & Peak released flow (as a random variable) \\
\hline$V_{\max }$ & Maximum storage (as a random variable) \\
\hline$p\left(Q_{\max }^{\mathrm{O}}\right)_{i}$ & $\begin{array}{l}\text { Probability that } Q_{\max }^{\mathrm{O}} \text { is found between } Q_{i, \max }^{\mathrm{O}} \\
\text { and } Q_{i+1, \max }^{\mathrm{O}}\end{array}$ \\
\hline$p\left(V_{\max }\right)_{j}$ & $\begin{array}{l}\text { Probability that } V_{\max } \text { is found between } V_{j, \max } \\
\text { and } V_{j+1, \max }\end{array}$ \\
\hline$D q\left(Q_{\max , i}^{\mathrm{O}}\right)$ & Damage associated to $Q_{i, \max }^{\mathrm{O}}$ \\
\hline$D v\left(V_{\max , j}\right)$ & Damage associated to $V_{j . \max }$ \\
\hline $\begin{array}{l}p \\
\left(\text { break } \mid V_{\max , j}\right)\end{array}$ & $\begin{array}{l}\text { Probability of dam failure if the volume } V_{j} \text {, max } \\
\text { is reached }\end{array}$ \\
\hline Cost $_{\text {break }}$ & Cost of damage if the dam does fail \\
\hline$I q$ & $\begin{array}{l}\text { Released flow risk index (expected cost of dam- } \\
\text { age due to released flows) }\end{array}$ \\
\hline$I v$ & $\begin{array}{l}\text { Storage risk index (expected cost of damage due } \\
\text { to stored volumes) }\end{array}$ \\
\hline Ir & Overall risk index (total expected cost of damage) \\
\hline$k q, k v$ & $\begin{array}{l}\text { Thresholds of damage referred to released flow } \\
\text { and storage, respectively }\end{array}$ \\
\hline FCL & Flood control level \\
\hline MCC & Maximum channel capacity \\
\hline $\mathrm{CDL}$ & Crest dam level \\
\hline$S_{I r}$ & Optimum balanced solution \\
\hline MILP & $\begin{array}{l}\text { Mixed integer programming model (used as } \\
\text { RFCM) }\end{array}$ \\
\hline$P$ & Total penalty to be minimised in MILP \\
\hline$P Q^{\mathrm{O}}$ & Release penalty (in MILP formulation) \\
\hline$P V$ & Storage penalty (in MILP formulation) \\
\hline$w q, w v$ & $\begin{array}{l}\text { Weights of the release and storage penalties, re- } \\
\text { spectively }\end{array}$ \\
\hline PVfcl & $\begin{array}{l}\text { Penalty corresponding to the volume at flood con- } \\
\text { trol level }\end{array}$ \\
\hline$b$ & Exponent of the release penalty function \\
\hline
\end{tabular}

Acknowledgements. The study was made possible by funds from the MODEX project (CGL2011-22868) "Physically-based modelling for characterisation of extreme hydrologic response under a probabilistic approach. Application to dam safety analysis and optimisation of reservoir operation during floods", funded the Ministry of the Economy and Competitiveness: Research, Development and Innovation Secretariat of the Government of Spain (previously, the Spanish Ministry of Science and Innovation). This research was also supported by Research Fellowship Program developed by the Technical University of Madrid (UPM), under the grant for doctoral research of Paola Bianucci at Hydroinformatics and Water Management Research Group.

Edited by: G. Boni

Reviewed by: three anonymous referees

\section{References}

Alemu, E., Palmer, R., Polebitski, A., and Meaker, B.: Decision support system for optimizing reservoir operations using ensemble streamflow predictions, J. Water Res. Plan. Manage., 137, 72-82, 2011.

Apel, H., Thieken, A. H., Merz, B., and Blöschl, G.: Flood risk assessment and associated uncertainty, Nat. Hazards Earth Syst. Sci., 4, 295-308, doi:10.5194/nhess-4-295-2004, 2004.

Arnell, N.: Expected annual damages and uncertainties in flood frequency estimation, J. Water Res. Plan. Manage., 115, 94-107, 1989.

Barredo, J. I., Saurí, D., and Llasat, M. C.: Assessing trends in insured losses from floods in Spain 1971-2008, Nat. Hazards Earth Syst. Sci., 12, 1723-1729, doi:10.5194/nhess-12-17232012, 2012.

Carvajal, C., Peyras, L., Arnaud, P., Boissier, D., and Royet, P.: Probabilistic modeling of floodwater level for dam reservoirs, J. Hydrol. Eng., 14, 223-232, 2009.

Chang, L.-C.: Guiding rational reservoir flood operation using penalty type genetic algorithm, J. Hydrol., 354, 65-74, 2008.

Cioffi, F. and Gallerano, F.: Multiobjective analysis of dam release flows in rivers downstream from hydropower reservoirs, App. Math. Model., 36, 2868-2889, 2012.

Correia, F. N., Saraiva, M. G., Da Silva, F. N., and Ramos, I.: Floodplain management in urban developing areas, Part 1, Urban Growth scenarios and land-use controls, Water Resour. Manag., 13, 1-21, 1999.

Duan, Q., Soorooshian, S., and Gupta, V.: Effective and efficient global optimization for conceptual rainfall-runoff models, Water Resour. Res., 28, 1015-1031, 1992.

Etoh, T., Murota, A., and Nakanishi, M.: SQRT-Exponential Type Distribution of Maximum, in: Proceedings of the International Symposium on Flood Frequency and Risk Analyses, 14-17 May 1986, Louisiana State University, edited by: Shing, V. P., Reidel Pub. Com., USA, 253-264, 1986.

Faber, A. and Stedinger, J.: Reservoir optimization using sampling SDP with ensemble streamflow prediction (ESP) forecasts, J. Hydrol., 249, 113-133, 2001.

Ginn, T. and Houck, M.: Calibration of an objective function for the optimization of real time reservoir operation, Water Resour. Res., 25, 591-603, 1989. 
Girón, F., Yagüe, J., and Martínez, R.: Flood routing in reservoirs base on hydrological forecasting, paper presented at Trans Twentieth International Congress on Large Dams, Q79-R25, ICOLD, Beijing, China, 403-417, 2000.

Gupta, H., Sorooshian, S., and Yapo, P.: Toward improved calibration of hydrologic models: Multiple and noncommensurable measures of information, Water Resour. Res., 34, 751-763, 1998.

Gupta, H., Sorooshian, S., and Yapo, P.: Status of automatic calibration for hydrologic models: Comparison with multilevel expert calibration, J. Hydrol. Eng., 4, 135-143, 1999.

ICOLD: Dams and floods, Guidelines and cases histories, Bulletin 125, International Commission of Large Dams, La Chapelle Montligeon, France, ISSN 0534-8293, 224 pp., 2003.

ICOLD: Role of dams in flood mitigation, Bulletin 131, International Commission of Large Dams, La Chapelle Montligeon, France, ISSN 0534-8293, 77 pp., 2006.

Jain, S., Yoganarasimhan, G., and Seth, S.: A risk-based approach for flood control operation of a multipurpose reservoir, Water Resour. Bull., 28, 1037-1043, 1992.

Kim, Y.-O., Eum, H.-I., Lee, E.-G., and Ko, I.: Optimizing operational policies of a Korean multireservoir system using sampling stochastic dynamic programming with ensemble streamflow prediction, J. Water Res. Plan. Manage., 133, 4-14, 2007.

Khu, S. and Madsen, H.: Multiobjective calibration with Pareto preference ordering: An application to rainfallrunoff model calibration, Water Resour. Res., 41, W03004, doi:10.1029/2004WR003041, 2005.

Koutsoyiannis, D., Efstratiadis, A., and Karavokiros, G.: A decision support tool for the management of multi-reservoir systems, J. Am. Water Resour. Assoc., 28, 945-958, 2002.

Labadie, J.: Optimal operation of multireservoir systems: State-ofthe-art review, J. Water Res. Plan. Manage., 130, 93-111, 2004.

Lund, J.: Floodplain planning with risk-based optimization, J. Water Res. Plan. Manage., 128, 202-207, 2002.

Madsen, H.: Automatic calibration of a conceptual rainfall-runoff model using multiple objectives, J. Hydrol., 235, 276-288, 2000.

Madsen, H.: Parameter estimation in distributed hydrological catchment modeling using automatic calibration with multiple objectives, Ad. Water Resour., 26, 205-216, 2003.

Malekmohammadi, B., Zahraie, B., and Kerachian, R.: Ranking solutions of multi-objective reservoir operation optimization models using multi-criteria decision analysis, Expert Syst. Appl., 38, 7851-7863, 2011.

McCarthy, G. T.: The Unit Hydrograph and Flood Routing, Conference of the North Atlantic Division USACE, USA, 24 June, 1938.

Mediero, L., Garrote, L., and Martín-Carrasco, F.: Probabilistic calibration of a distributed hydrological model for flood forecasting, Hydrol. Sci. J., 56, 1129-1149, doi:10.1080/02626667.2011.610322, 2011.

Ministerio de Fomento: Máximas lluvias diarias en la España peninsular - Dirección General de Carreteras, Ministerio de Fomento - Centro de publicaciones, Madrid, España, 1999.
MOPU (Ministerio de Obras Públicas y Urbanismo): Instrucción de carreteras 5.2-IC "Dreanje Superficial”, Dirección General de Carreteras, BOE 123, 23/05/1990, 389-396, 1990.

Needham, J., Watkins Jr., D., Lund, J., and Nanda, K.: Linear programming for flood control in the Iowa and Des Moines rivers, J. Water Res. Plan. Manage., 126, 1291-1297, 2000.

Ngo, L., Madsen, H., and Rosbjerg, D.: Simulation and optimisation modelling approach for operation of the Hoa Binh reservoir, Vietnam, J. Hydrol., 336, 269-281, 2007.

Raman, H. and Chandramouli, V.: Deriving a general operating policy for reservoirs using neural network, J. Water Res. Plan. Manage., 122, 342-347, 1996.

Rani, D. and Moreira, M.: Simulations-optimization modeling: A survey and potential application in reservoir systems operation, Water Resour. Manag., 24, 1107-1138, 2010.

Rasekh, A., Afshar, A., and Afshar, M.: Risk-cost optimization of hydraulic structures: Methodology and case study, Water Resour. Manag., 24, 2833-2851, 2010.

SCS (USDA Soil Conservation Service): National Engineering Handbook, Section 4: Hydrology, US Department of Agriculture, Washington, DC, USA, 1972.

Sordo-Ward, A., Garrote, L., Martín-Carrasco, F., and Bejarano, M.: Extreme flood abatement in large dams with fixed-crest spillways, J. Hydrol., 466-467, 60-72, 2012.

SPANCOLD (Spanish National Committee on Large Dams): Guía técnica de seguridad de presas: No. 4, Avenida de Proyecto, SPANCOLD, Madrid, Spain, 1997.

USACE: Analysis of flood control operation of the Iowa/Des Moines River Reservoir System using linear programming techniques, Rep. PR-38, Hydrologic Engrg, Ctr. Davis, California, 1999.

Valdes, J. and Marco, J.: Managing reservoir for flood control, paper presented at US-Italy Research Workshop on the Hydrometeorology, Impacts and Management of Extreme Floods, Perugia, Italy, November, 1995.

Wagener, T., Lees, M., and Wheater, H.: Monte-Carlo Analysis Toolbox User Manual. Civil and Environmental Engineering Department, Imperial College of Science Technology and Medicine, London, UK, available at: http://ewre.cv.ic.ac.uk/ (last access: 7 November 2011), 2001.

Wei, C.-C. and Hsu, N.-S.: Multireservoir real-time operations for flood control using balanced water level index method, J. Environ. Manage., 88, 1624-1639, 2008.

Windsor, J.: Optimization model for the operation of flood control systems, Water Resour. Res., 9, 1219-1225, 1973.

Wurbs, R.: Comparative evaluation of generalized river/reservoir system models, TR-282, Texas Water Resources Institute, Texas A\&M University, 2005.

Yapo, P., Gupta, H., and Sorooshian, S.: Automatic calibration of conceptual rainfall-runoff models: sensitivity to calibration data, J. Hydrol., 181, 23-48, 1996.

Yapo, P., Gupta, H., and Sorooshian, S.: Multi-objective global optimization for hydrologic models, J. Hydrol., 204, 83-97, 1998. 